\title{
Seismic Response and Evaluation of SDOF Self-Centering Friction Damping Braces Subjected to Several Earthquake Ground Motions
}

\author{
Jong Wan $\mathrm{Hu}^{1,2}$ and Myung-Hyun $\mathrm{Noh}^{3}$ \\ ${ }^{1}$ Department of Civil and Environmental Engineering, Incheon National University, 12-1 Songdo-dong, Yeonsu-gu, \\ Incheon 406-840, Republic of Korea \\ ${ }^{2}$ Incheon Disaster Prevention Research Center, Incheon National University, 12-1 Songdo-dong, Yeonsu-gu, \\ Incheon 406-840, Republic of Korea \\ ${ }^{3}$ POSCO Product Application Center, 180-1 Songdo-dong, Yeonsu-gu, Incheon 406-840, Republic of Korea
}

Correspondence should be addressed to Myung-Hyun Noh; mnoh@posco.com

Received 19 June 2015; Revised 21 August 2015; Accepted 24 August 2015

Academic Editor: Stefano Sorace

Copyright (c) 2015 J. W. Hu and M.-H. Noh. This is an open access article distributed under the Creative Commons Attribution License, which permits unrestricted use, distribution, and reproduction in any medium, provided the original work is properly cited.

\begin{abstract}
This paper mainly deals with seismic response and performance for self-centering friction damping braces (SFDBs) subjected to several maximum- or design-leveled earthquake ground motions. The self-centering friction damping brace members consist of core recentering components fabricated with superelastic shape memory alloy wires and energy dissipation devices achieved through shear friction mechanism. As compared to the conventional brace members for use in the steel concentrically braced frame structure, these self-centering friction damping brace members make the best use of their representative characteristics to minimize residual deformations and to withstand earthquake loads without member replacement. The configuration and response mechanism of self-centering friction damping brace systems are firstly described in this study, and then parametric investigations are conducted through nonlinear time-history analyses performed on numerical single degree-of-freedom spring models. After observing analysis results, adequate design methodologies that optimally account for recentering capability and energy dissipation according to their comparative parameters are intended to be suggested in order to take advantage of energy capacity and to minimize residual deformation simultaneously.
\end{abstract}

\section{Introduction}

The steel concentrically braced frames (CBFs) have been used as lateral load-resisting and high performance structures constructed around the perimeter of the building. These CBFs are considered to be significantly ductile systems capable of permitting large inelastic deformations without strength degradation and structural instability [1-5]. In particular, the brace members which are easier to be replaceable in the frame structure are designed to accommodate large inelastic deformation with an aim to minimize the damage of primary structural members, such as beams, columns, and walls [6-8]. After 1994 Northridge and 1995 Kobe earthquake events, some researches have progressively focused on the seismic design strategy that can be allowed to fully integrate passive damping devices representatively termed as energy dissipation systems into the brace member $[9,10]$. The viscous fluid, electromagnetic, viscoelastic, and metallic yield, and frictional dampers belong to such passive energy dissipation devices [11-17]. The friction dampers exhibit stable energy dissipation generated by simple friction mechanisms developed on the sliding shear surfaces, as compared to other types of passive dampers [18, 19]. Their hysteretic behaviors are stably maintained with constant slip resistance during a number of cyclic loads. The slip resistance loads are conveniently regulated by either quantifying bolt pretension or controlling surface condition [20,21]. Therefore, the friction dampers have been widely used in the practical construction field for seismic design owing to simple mechanism, easy fabrication, and sustainable maintenance. 
The application of these damper devices to the brace member makes a big contribution to the protection of primary structural members from severe damage. Although the friction dampers improve seismic performance with respect to impact absorption and energy dissipation in the entire frame structure, a considerable amount of residual interstory drifts is likely to occur due to permanent deformations caused by impaired friction damping systems after strong earthquake events. The large residual interstory drifts make the residents feel uncomfortable and significantly increase the cost of repair or replacement $[3,22,23]$. The selfcentering retrofit systems which can automatically recover their original configuration have been recently attracting considerable attention in the high seismicity area because they play an important role to reduce permanent deformation occurring at the entire frame structure [24, 25].

The flag-shaped hysteresis loop results in the behavior of the typical self-centering system. Superelastic shape memory alloy (SMA) materials that possess flag-shaped stress-strain behavior have been utilized as self-centering systems for the purpose of minimizing residual interstory drifts in the whole building structure [26, 27]. As shown in Figure 1, these superelastic SMA materials perfectly recover their original configuration without residual strain during stress-induced martensite transformation. The superelastic SMA wires have been seen as damper devices incorporation installed on the bracing member. Related experiments and simulations have been carried out to explore the application of the SMA-based self-centering devices in the passive vibration control systems. For instance, Clark et al. [28] performed a study on the steel braced frame which was installed with the recentering devices made by the Nitinol SMA wires. The several loops of the Nitinol SMA wires were wound around two cylindrical fixed anchors to combine the friction damper braces $[28,29]$. Several different prototypes of the self-centering friction damping braces (SFDBs) that were designed, implemented, and tested can be also seen in the references [29]. The presented test results confirm that proposed braces contain inherent characteristics for great versatility, simple working mechanism, recentering capability, high stiffness at the small displacement especially, and energy dissipation capacity. Therefore, the behavior of the best SFDB system, which is displayed with zero residual deformation as well as enhanced energy dissipation at the same time, can be reproduced by properly adjusting the ratio between recentering force and slip resistance $[28,29]$. The design guidelines associated with the determination of the ideal parametric ratio are necessary to be introduced in order to get the utmost out of recentering capability and energy dissipation in the SFDB system. Most of the existing researches have only focused on the development of new passive control systems and unfortunately lack optimal design investigation based on performance evaluation with variable parameters.

The purpose of this study is to examine seismic performance and evaluation of the SFDB systems designed with parametric properties through observing the response of the numerical single degree-of-freedom (SDOF) spring models under several seismic forces. The performance-based

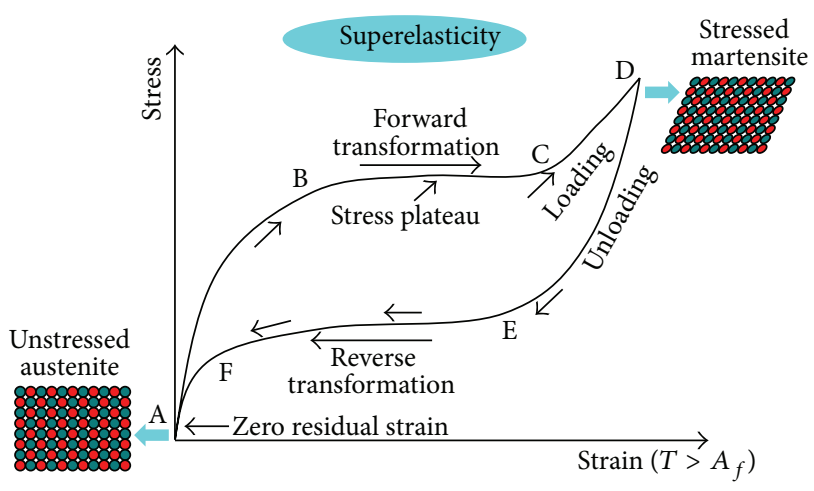

FIGURE 1: Hysteresis loop of superelastic shape memory alloy (SMA) materials.

optimal design methodologies for the SFDB system as one of the representative smart self-centering devices are also presented in this study on the basis of these numerical analysis results. The response mechanisms made up of both recentering behavior and slip friction are modeled as corresponding SDOF component springs calibrated to experimental test results and idealized by the stiffness models generally used for numerical simulation. The different hysteresis curves are reproduced by using these component springs modelled with various prototype scale parameters through nonlinear time-history analyses. For the analyses, two sets of ground motion data records (i.e., 20 basic design earthquake (BDE) records and 20 maximum considered earthquake (MCE) records) are selected for the nonlinear time-history analyses. The fact that recentering capability correlates with energy dissipation capacity in the SFDB system will be verified through observing the analysis results. Finally, in this study, the optimal ratios between prototype design parameters are also proposed after comparative studies according to the intensity of the used ground motions with an intension to simultaneously maximize energy dissipation capacity and recentering capability in the SFDB system.

\section{Response Mechanism}

The SFDB can be utilized as part of the brace system so as to effectively withstand the lateral load transmitted from seismic force. The details of the SFDBs are schematically illustrated in Figure 2. The SFDBs are composed of two shear plates, four shear bolts, slotted bolt holes, and superelastic SMA stranded wires wound around the fixed anchors. The shear plates are moveable by means of direct shear forces acting along the longitudinal direction of the slotted bolt holes. The shear friction mechanism which causes stable energy dissipation has a significant influence on roughness condition between shear faying surfaces and normal force determined by bolt adjustment length. The superelastic SMA stranded wires are only available to resist external excitation under tension and principally provide recentering capability to the SFDB system. 


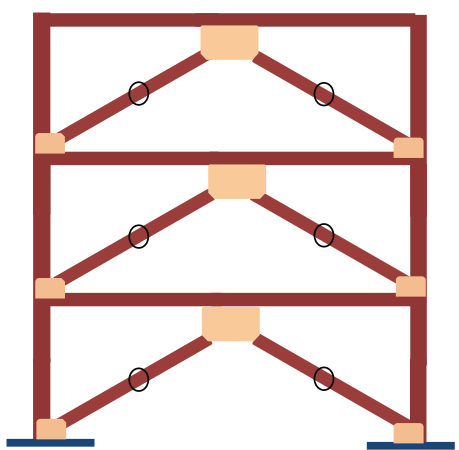

O SFDB systems

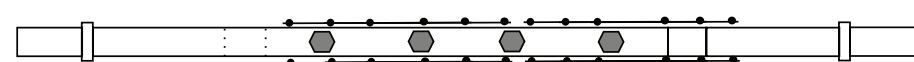

(b) Front view

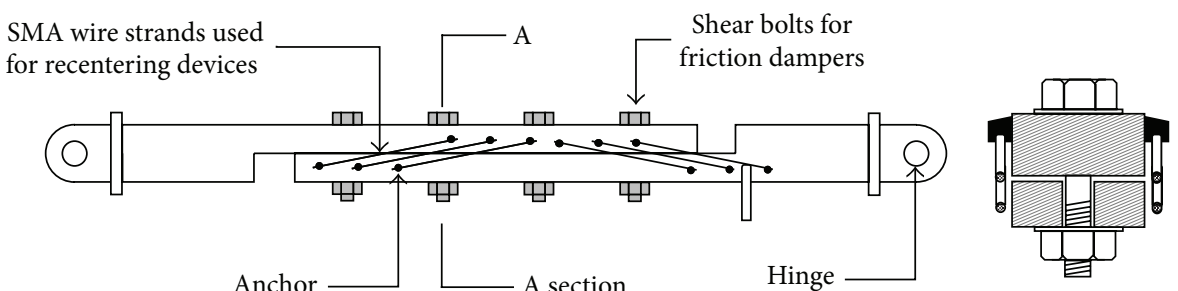

(c) Side view

(d) A-A section

FIGURE 2: Design and application of the self-centering friction damping brace (SFDB) system.

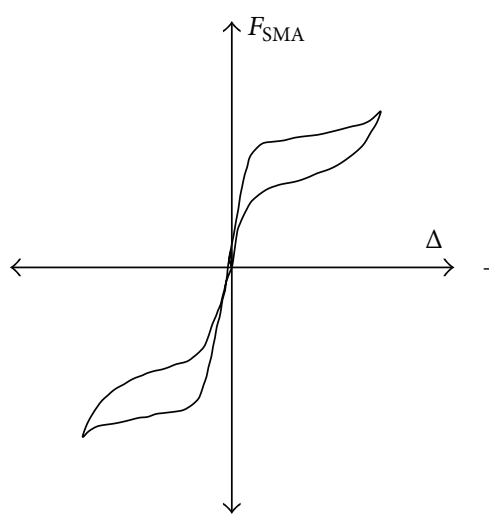

(a) Self-centering by superelastic SMA wires

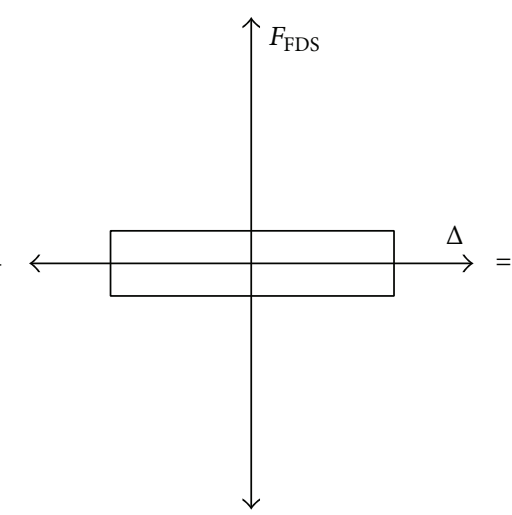

(b) Energy dissipation by friction damper

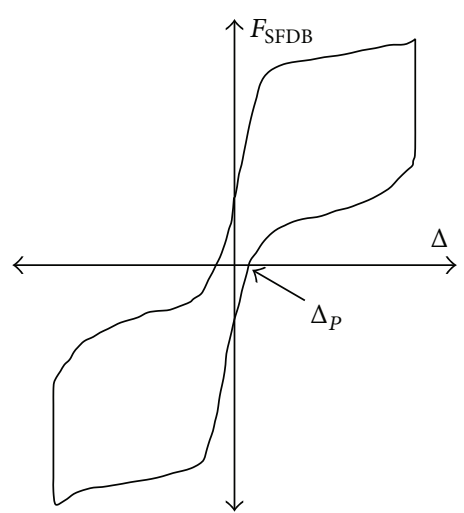

(c) Total behavior of SFDB systems

FIGURE 3: Response mechanism of SFDB systems.

The response mechanism of the SFDB system is presented in Figure 3. The stress-induced phase transformation from martensite to austenite, which is referred to as reverse transformation upon unloading (see Figure 1), is able to bring about recentering behavior at room temperature [3033]. This unique characteristic is called superelasticity or pseudoelasticity and provides the ability to recover original configuration without additional heat treatment for SMA materials. Therefore, self-centering capability in the SFDB system is mainly attributed to the hysteretic behavior of the superelastic SMA wires as shown in Figure 3(a). As illustrated in Figure 3(b), the rectangular hysteretic loop indicates effective energy dissipation arising due to durable frictional behavior. This loop is determined by slip resistance load and slip distance. The slip resistance load is affected by initial bolt force and surface roughness condition while the limit of slip distance is determined by the length of the slotted bolt holes. Stable and considerable energy dissipation can be expected at the friction response because constant slip resistance loads are kept over loading cycles. However, energy dissipation induced by friction mechanism is likely to generate considerable permanent deformation in the hysteretic loop. The hysteretic behavior of the SFDB system can be simulated by superposing flag-shaped SMA behavior and friction effect as follows (see also Figure 3(c)):

$$
F_{\mathrm{SFDB}}=F_{\mathrm{SMA}}+F_{\mathrm{FDS}} \text {. }
$$

Accordingly, the combined hysteresis loops for the SFDB systems are expected to achieve nearly self-centering behavior with enhanced energy dissipation by adequately regulating the ratio between the yield strength of superelastic SMA wires and friction forces.

\section{Analytical Modeling}

The analytical models made up of nonlinear component springs were constructed to reproduce the behavior of the SFDBs by using the OpenSEES program [34]. The modeling attributes for single degree-of-freedom (SDOF) SFDB models are presented in Figure 4. The analytical SFDB model consists of two component springs corresponding to superelastic SMA stranded wires and friction damper systems. Taking into account how to interact with each component mechanism during force transfer, these component springs were 


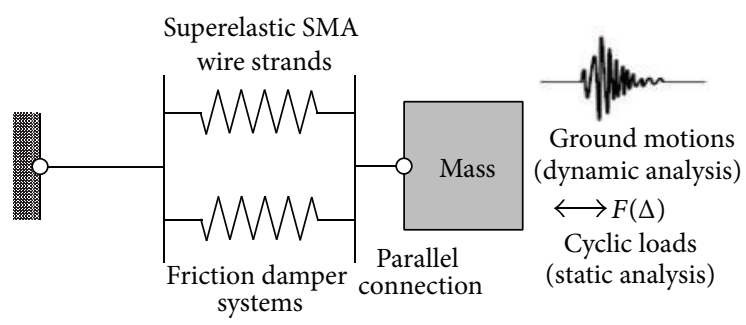

(a) Component spring model

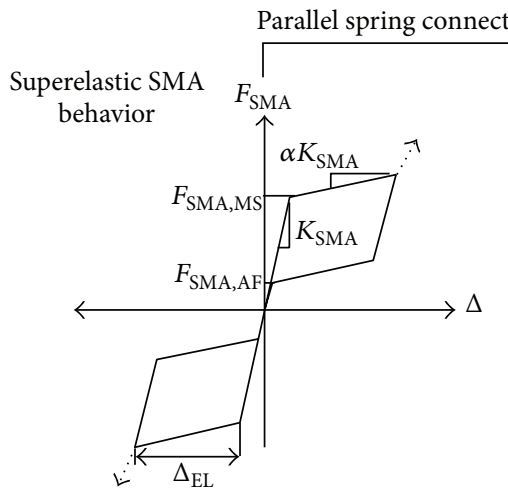

Flag-shaped hysteresis SMA behavior (UMAT material)
Friction damper
behavior

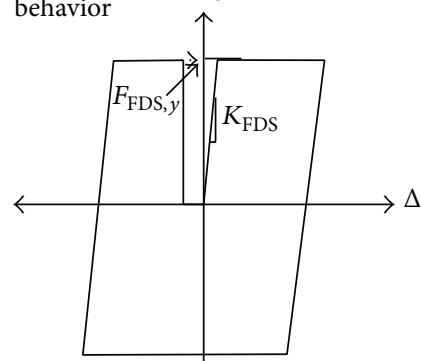

Isotropic hardening slip behavior (hardening material)

(b) Stiffness models for individual component springs

FIGURE 4: Modeling attributes for SFDB component spring models.

assembled in parallel to simulate the behavior of the SFDB. In addition, lumped mass should be connected to the end of the assembled component springs so as to generate the axial forces transferred from ground accelerations. The transient equilibrium algorithm based on the Newmark method was introduced to compute the time-dependent dynamic problem. The effective damping generated by the Rayleigh command in the OpenSEES program was added to this algorithm. The ground motions were directly applied to the SDOF SFDB spring models as shown in Figure 4(a).

The cyclic force and deformation curves for individual component springs were idealized as the multilinear stiffness models as presented in Figure 4(b). The key parameters that formulate the stiffness model for superelastic SMA behavior, that is, initial stiffness $\left(K_{\mathrm{SMA}}\right)$, martensite phase transformation starting force $\left(F_{\text {SMA,MS }}\right)$, austenite phase transformation ending force $\left(F_{\mathrm{SMA}, \mathrm{AF}}\right)$, strain hardening ratio $(\alpha)$, and phase transformation distance $\left(\Delta_{\mathrm{EL}}\right)$, were estimated based on the cyclic material full-out test results $[29,30]$. Therefore, this stiffness model can be denoted as a series of the straight lines which agree with the process of individual phase transformations. The yielding of friction damper system behavior $\left(F_{\mathrm{FDS}, y}\right)$ was obtained by adjusting the initial pretension of shear bolts. The stiffness model for the friction damper system was simulated by utilizing the isotropic hardening uniaxial material given to the OpenSEES program. The stiffness model used to reproduce the behavior of the superelastic SMA stranded wires was simulated by the user-defined material (UMAT) codes presented in the references [32, 35] due to the lack of the default uniaxial material command in the program. All of the uniaxial material properties were assigned to component springs modeled as nonlinear zerolength elements for the purpose of simulating the behavior of SFDBs through dynamic time-history analyses.

As shown in Figure 5, the component spring models were calibrated to the test results obtained from the experimental research with an aim to verify the adequacy of modeling attributes illustrated herein. The comparative experiments were performed by Zhu and Zhang [29] in an effort to exam the behavior of the scaled SFDB specimens cyclically tested. The hysteretic curves obtained from experimental tests are plotted as solid lines while those from numerical analyses are plotted as dashed lines. Each of the hysteretic curves is displayed with various friction force levels determined according to initial bolt pretension, thereby providing different energy dissipation and recentering capability for individual SFDB specimens. Both resulting curves compared to each other show relatively good agreements with respect to initial stiffness, postyielding strength, ultimate strength, and even pinching points. Therefore, it can be assured that the component spring models used for numerical analyses are adequate to reproduce the behavior of the SFDB in accordance with various design parameters.

On the basis of calibration to the experimental results, five SFDB model cases are designed with comparative parameters illustrated in Table 1. The comparative parameters indicating different friction forces with constant recentering capability 

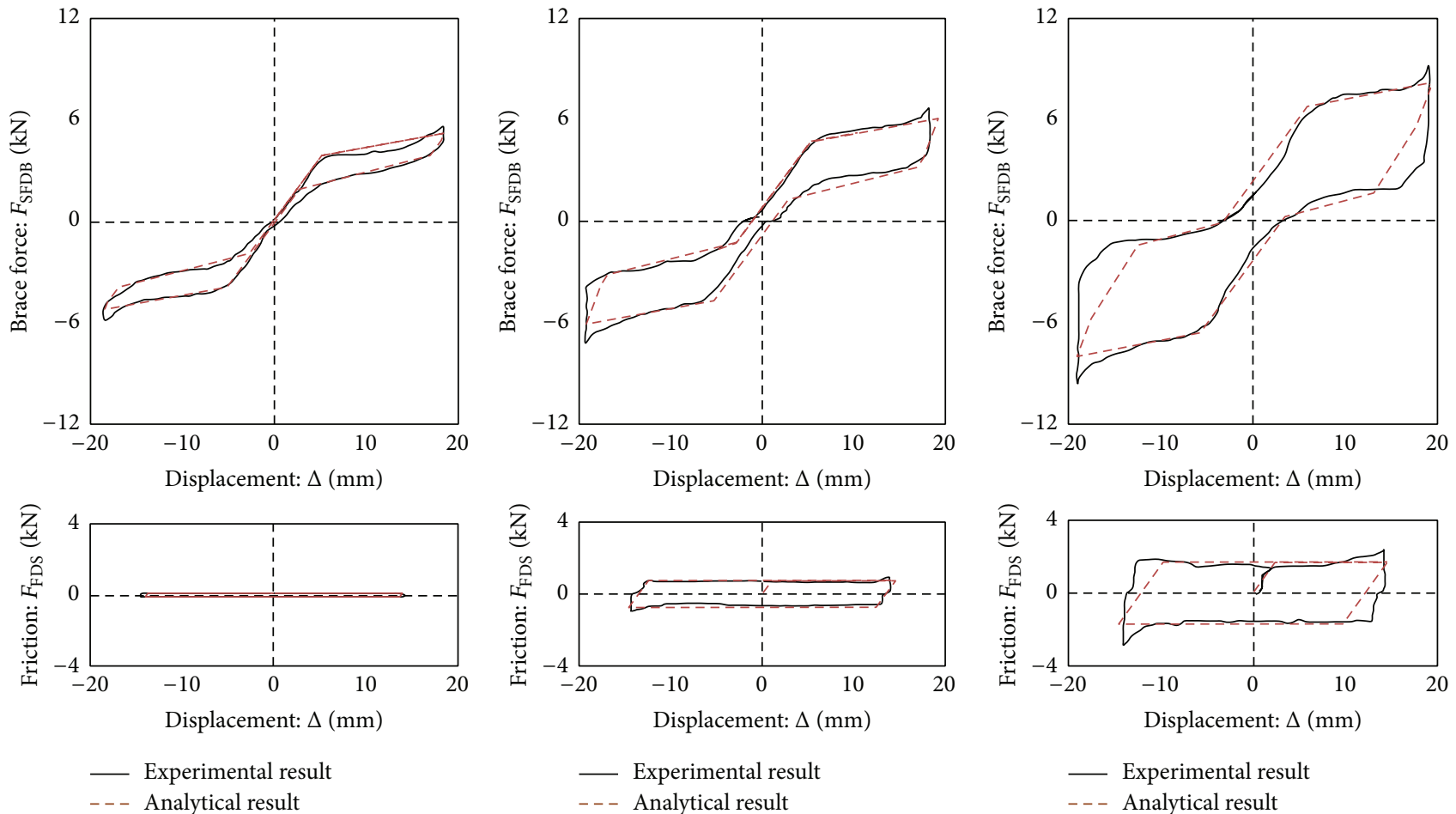

_ Experimental result

- - Analytical result

- - Analytical result

_ Experimental result

- - Analytical result

(a) $F_{\mathrm{FDS}, y}=0 \mathrm{kN}$ case

(b) $F_{\mathrm{FDS}, y}=1 \mathrm{kN}$ case

(c) $F_{\mathrm{FDS}, y}=2 \mathrm{kN}$ case

Figure 5: Comparisons of experimental test results to analytical test results.
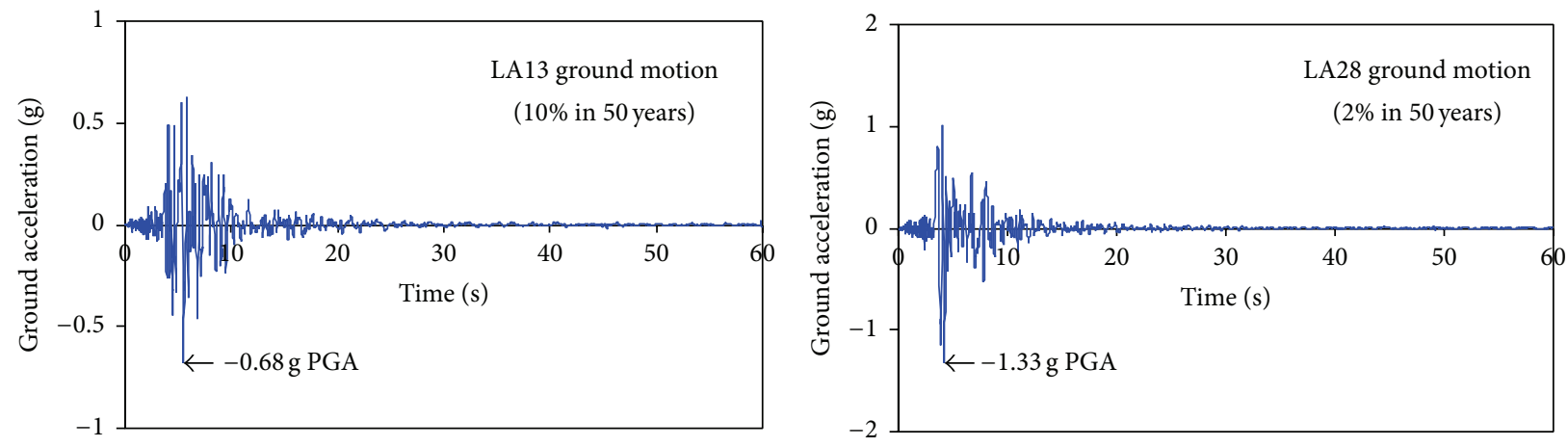

(a) Ground motion data
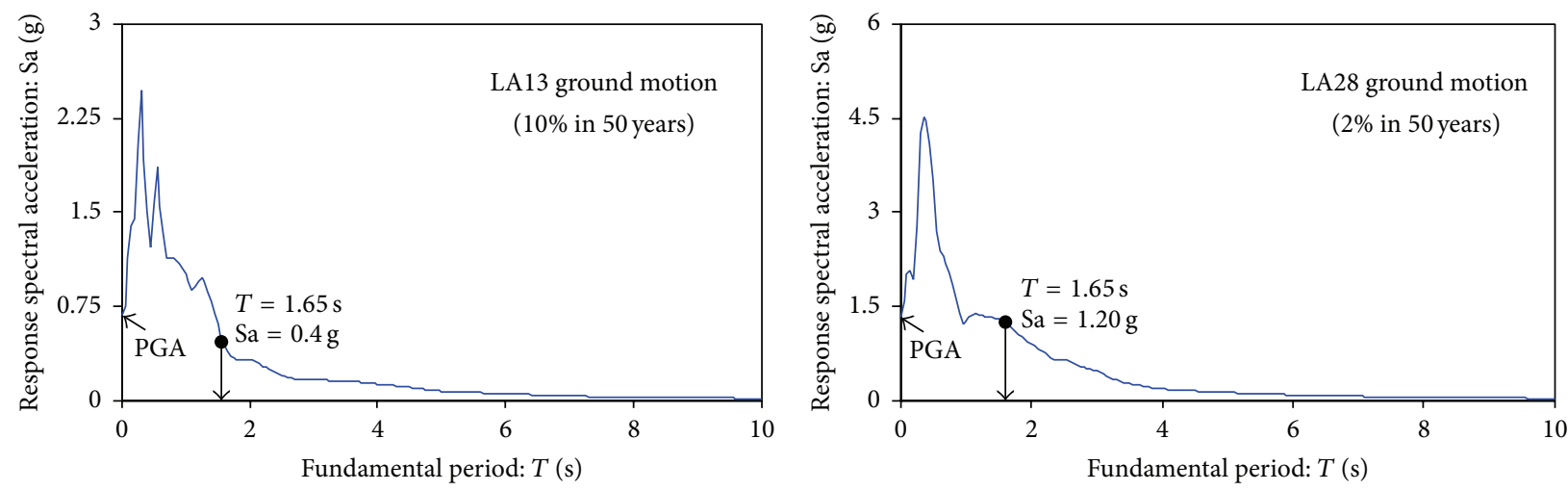

(b) Response spectral acceleration for SDOF systems

FIGURE 6: Representative ground motion data and response spectral accelerations (1.0 Scale Factor (SF)). 


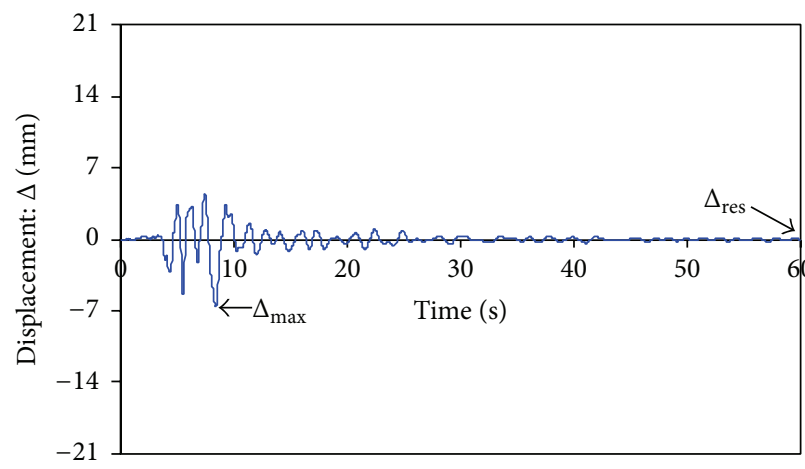

(a) Case 1 model under LA13 with $0.5 \mathrm{SF}$

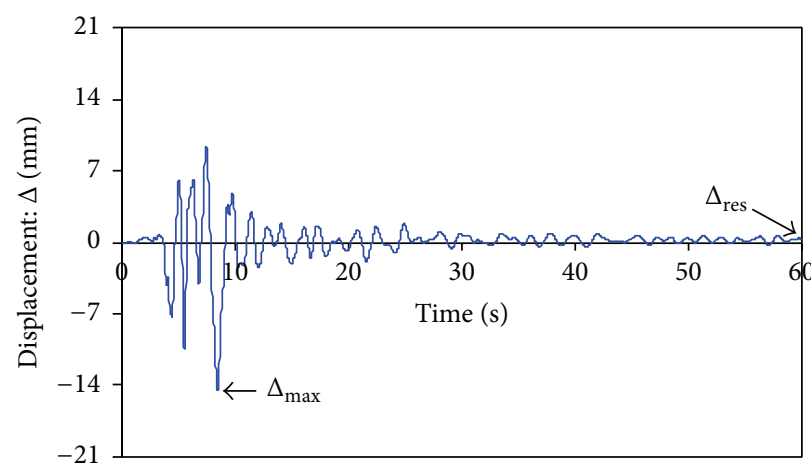

(c) Case 1 model under LA13 with $1.0 \mathrm{SF}$

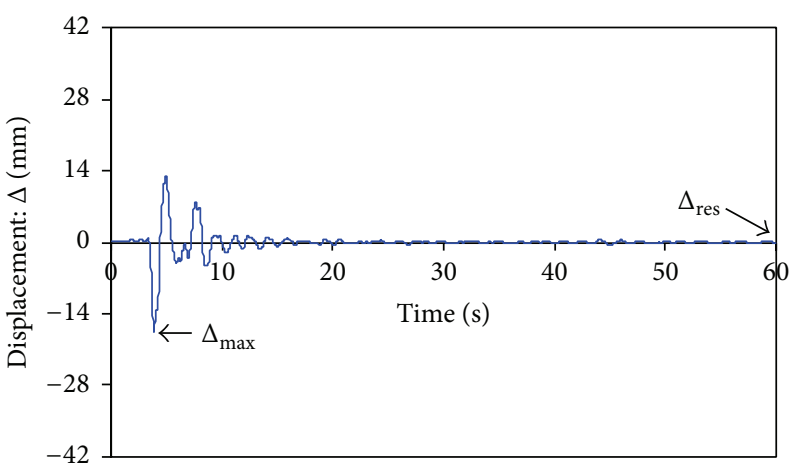

(b) Case 1 model under LA28 with $0.5 \mathrm{SF}$

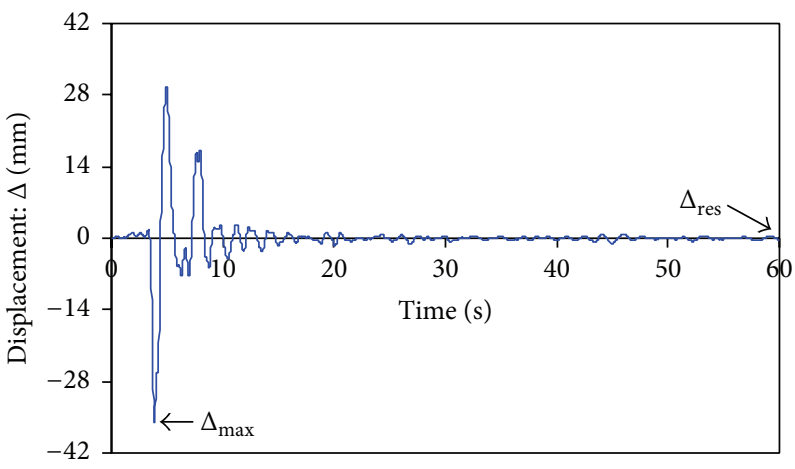

(d) Case 1 model under LA28 with $1.0 \mathrm{SF}$

Figure 7: Displacement versus time curves for the SFDB model (Case 1) under representative ground motions with Scale Factors (SFs).

TABLE 1: Parametric details for individual model cases.

\begin{tabular}{|c|c|c|c|}
\hline Model ID & \multicolumn{2}{|r|}{ Superelastic SMA wires } & Friction dampers \\
\hline $\begin{array}{l}\text { Case } 1 \\
(\gamma=0.33)\end{array}$ & \multicolumn{2}{|c|}{$\begin{array}{l}K_{\mathrm{SMA}}=0.74 \mathrm{kN} / \mathrm{mm}, \alpha=0.135, \Delta_{\mathrm{EL}}=14.8 \mathrm{~mm} \\
F_{\mathrm{SMA}, \mathrm{MS}}=3.80 \mathrm{kN}, F_{\mathrm{SMA}, \mathrm{AF}}=2.10 \mathrm{kN}\end{array}$} & $\begin{array}{l}K_{\mathrm{FDS}}=0.72 \mathrm{kN} / \mathrm{mm} \\
F_{\mathrm{FDS}, y}=0.70 \mathrm{kN}\end{array}$ \\
\hline $\begin{array}{l}\text { Case } 2 \\
(\gamma=0.67)\end{array}$ & 氠 $\quad 6$ & & $\begin{array}{c}K_{\mathrm{FDS}}=0.72 \mathrm{kN} / \mathrm{mm} \\
F_{\mathrm{FDS}, y}=1.40 \mathrm{kN}\end{array}$ \\
\hline $\begin{array}{l}\text { Case } 3 \\
(\gamma=1.00)\end{array}$ & $\sum_{\substack{5 \\
1}}^{\mathbb{3}} 0$ & & $\begin{array}{l}K_{\mathrm{FDS}}=0.72 \mathrm{kN} / \mathrm{mm} \\
F_{\mathrm{FDS}, y}=2.10 \mathrm{kN}\end{array}$ \\
\hline $\begin{array}{l}\text { Case } 4 \\
(\gamma=1.33)\end{array}$ & $\begin{array}{c}\ddot{0} \\
\ddot{0}\end{array}-6$ & 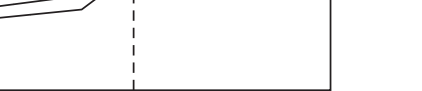 & $\begin{array}{l}K_{\mathrm{FDS}}=0.72 \mathrm{kN} / \mathrm{mm} \\
F_{\mathrm{FDS}, y}=2.80 \mathrm{kN}\end{array}$ \\
\hline $\begin{array}{l}\text { Case } 5 \\
(\gamma=1.67)\end{array}$ & \multicolumn{2}{|r|}{ Displacement: $\Delta(\mathrm{mm})$} & $\begin{array}{c}K_{\mathrm{FDS}}=0.72 \mathrm{kN} / \mathrm{mm} \\
F_{\mathrm{FDS}, y}=3.50 \mathrm{kN}\end{array}$ \\
\hline
\end{tabular}

were selected to examine relationship between self-centering effect and energy dissipation capacity. The friction force levels ranging from $0.7 \mathrm{kN}$ to $3.5 \mathrm{kN}$ were uniformly divided into five sections in order to easily check whether energy dissipation relates to the amount of recoverable displacement. Furthermore, all of the SFDB models were designed with the same recentering capability by using identical SMA stranded wires. In particular, Cases 1 and 3 analysis models were designed with the similar friction force levels to experimental models for the purpose of examining the behavior of the experimental models subjected to several ground motions with more details (see Figure 5). The key parameters of SMA stranded wires such as $K_{\mathrm{SMA}}, \alpha, \Delta_{\mathrm{EL}}, F_{\mathrm{SMA}, \mathrm{MS}}$, and $F_{\mathrm{SMA}, \mathrm{AF}}$ are taken as the values of $0.74 \mathrm{kN} / \mathrm{mm}, 0.135,14.8 \mathrm{~mm}, 3.80 \mathrm{kN}$, and $2.10 \mathrm{kN}$, respectively. The SFDB models can be classified according to the force ratio defined as follows:

$$
\gamma=\frac{F_{\mathrm{FDS}, \mathrm{y}}}{F_{\mathrm{SMA}, \mathrm{AF}}} .
$$

This force ratio is considered to be one of most important factors for optimal design in the SFDB system.

\section{Nonlinear Dynamic Analysis}

The seismic behavior and performance of the SFDB structures were investigated through nonlinear dynamic timehistory analyses performed on five component spring models 


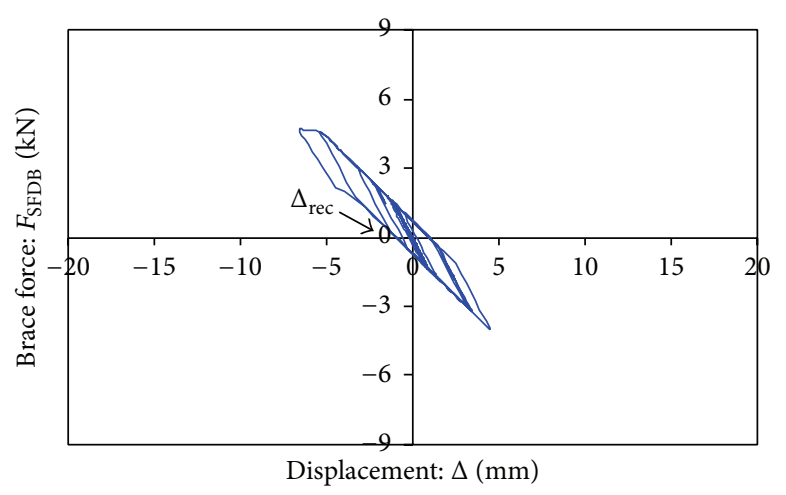

(a) Case 1 model under LA13 with $0.5 \mathrm{SF}$

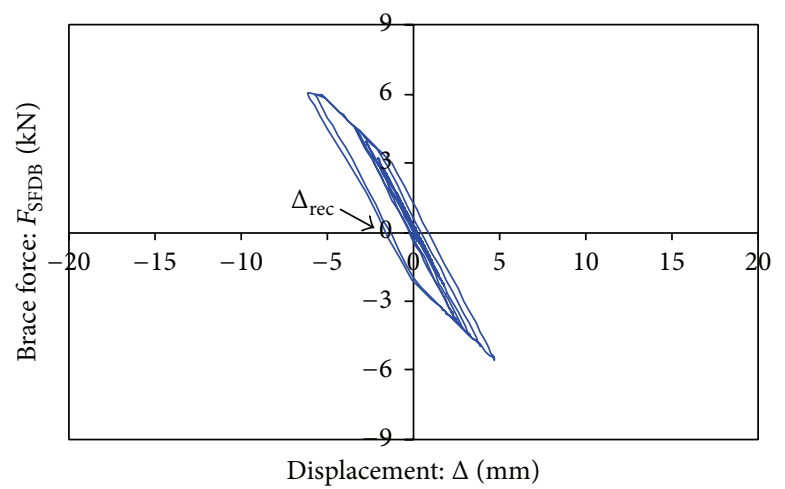

(c) Case 3 model under LA13 with $0.5 \mathrm{SF}$

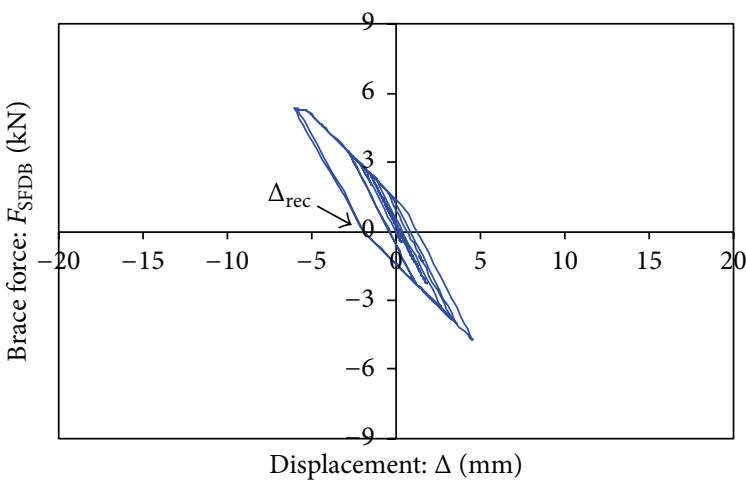

(b) Case 2 model under LA13 with $0.5 \mathrm{SF}$

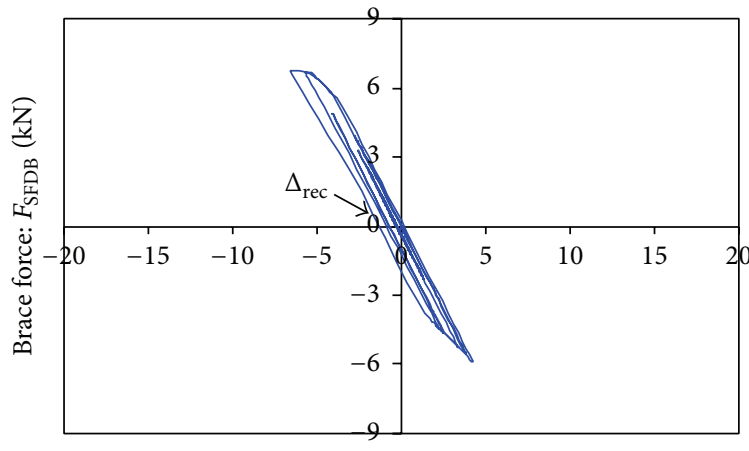

Displacement: $\Delta(\mathrm{mm})$

(d) Case 4 model under LA13 with $0.5 \mathrm{SF}$

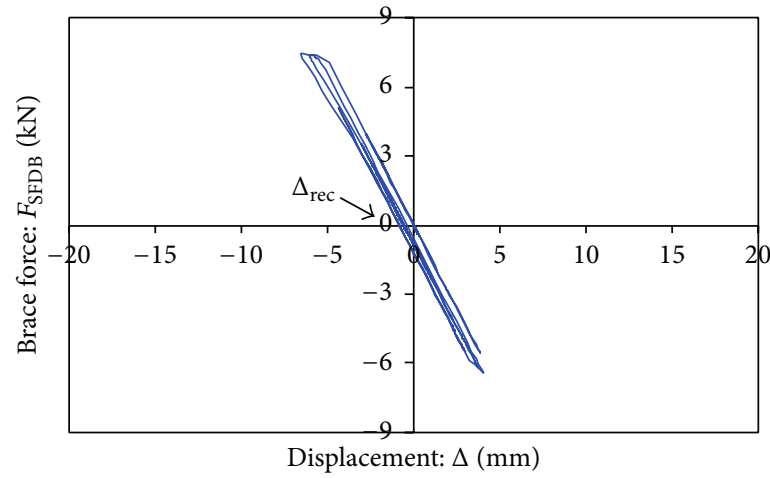

(e) Case 5 model under LA13 with $0.5 \mathrm{SF}$

FIGURE 8: Force and displacement curves for individual SFDB models under the LA13 ground motion with 0.5 SF.

corresponding to SFDB model cases presented in Table 1. These nonlinear dynamic analyses were conducted by directly applying nonlinear component spring models to LA (Los Angeles) ground motions on the OpenSEES program. The ground motion records presented herein were constructed as a part of the SAC project [36]. Two different seismic hazard levels representing (a) basic design earthquake (BDE) commensurate with a seismic hazard level of $10 \%$ probability of exceedance in 50 years (LA01 to LA20 in Table 2) and (b) maximum considered earthquake (MCE) commensurate with a seismic hazard level of $2 \%$ probability of exceedance in 50 years (LA21 to LA40 in Table 3) were treated in this study. The BDE response spectrum was generally considered to be $2 / 3$ of the MCE one [36]. Two sets of 40 ground motion records are illustrated in Tables 2 and 3 with more detail.

Two LA ground motion datasets (LA13 and LA28) were firstly selected as presented in Figure 6, and then nonlinear dynamic time-history analyses were conducted with two scale factors (SFs) of the used ground motions. The LA13 ground motion has 60-second duration time with the peak ground acceleration (PGA) value of $0.68 \mathrm{~g}$ and appertains to $\mathrm{BDE}$ ground motion. On the other hand, the LA28 ground motion has 60 -second duration time with the PGA value of $1.33 \mathrm{~g}$ and appertains to MCE ground motion. The values of $0.4 \mathrm{~g}$ (for LA13 ground motion) and $1.2 \mathrm{~g}$ (for LA28 ground motion) are displayed as response spectral accelerations ( $\mathrm{Sa}$ ) measured at 


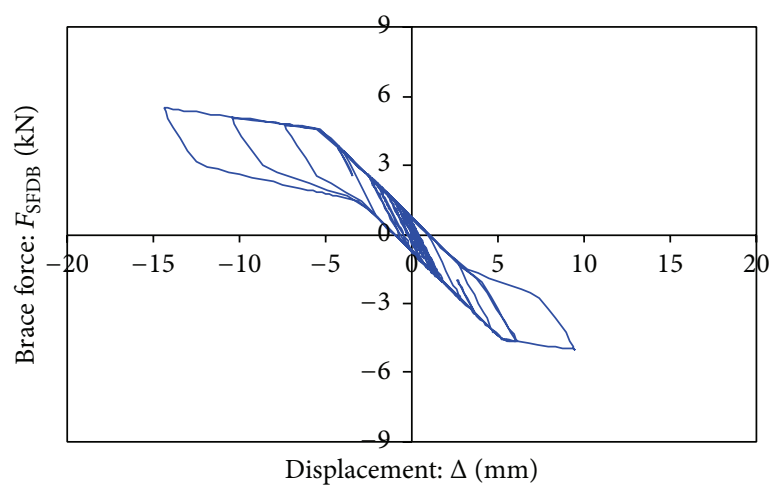

(a) Case 1 model under LA13 with $1.0 \mathrm{SF}$

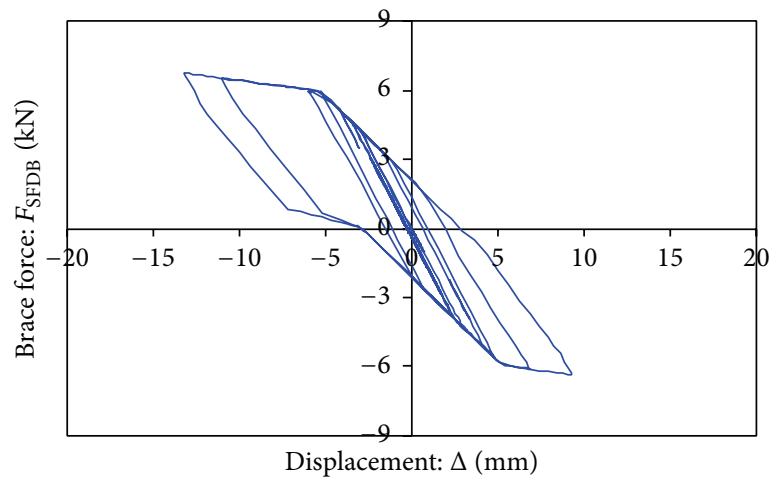

(c) Case 3 model under LA13 with $1.0 \mathrm{SF}$

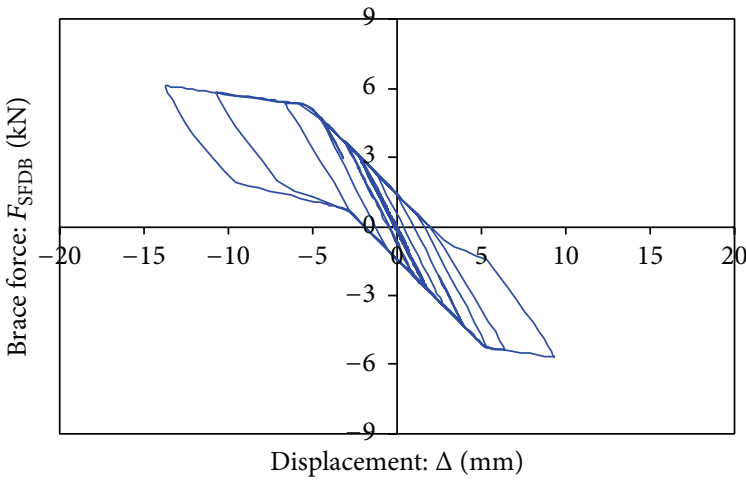

(b) Case 2 model under LA13 with $1.0 \mathrm{SF}$

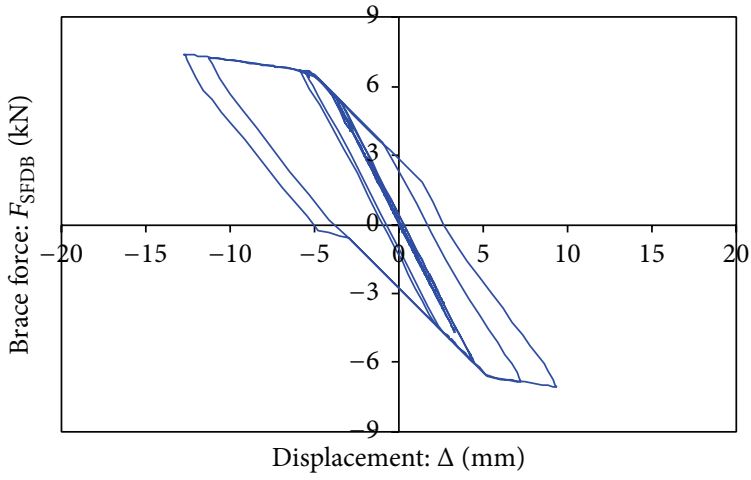

(d) Case 4 model under LA13 with $1.0 \mathrm{SF}$

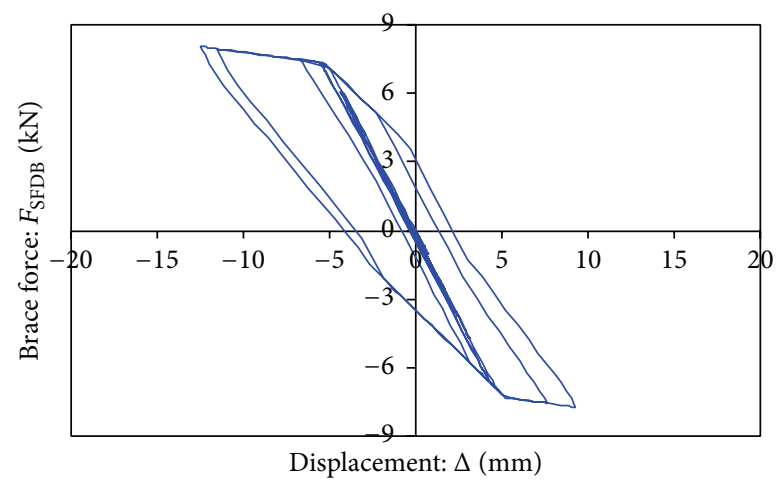

(e) Case 5 model under LA13 with $1.0 \mathrm{SF}$

FIGURE 9: Force and displacement curves for individual SFDB models under the LA13 ground motion with 1.0 SF.

the fundamental period of the SDOF system $(T)$. This implies that the LA28 ground motion with relatively higher response spectral acceleration can generate larger seismic force than the LA13 ground motion.

Displacement versus time curves for the SFDB model (Case 1) under two representative seismic ground motions with the values of 0.5 and $1.0 \mathrm{SF}$ are presented in Figure 7. The amount of maximum displacement $\left(\Delta_{\max }\right)$ is proportional to the increasing SFs. Meanwhile, the occurrence time of maximum displacement is identical under the same applied ground motion regardless of the SF. For instance, Case 1 model under LA13 ground motion with 0.5 and $1.0 \mathrm{SF}$ has about $7 \mathrm{~mm}$ and $14 \mathrm{~mm}$ maximum displacement, respectively, at the time of about 9.0 seconds. Case 1 model under LA28 ground motion exhibits approximately 2.5 times larger maximum displacement than that under LA13 ground motion owing to higher response spectral acceleration. The excellent recentering capability enables this model to possess almost zero residual displacement $\left(\Delta_{\text {res }}\right)$ in the time-history curve (see Figure 7). In addition to the self-centering effect of the SFDB model, energy dissipation can be observed at the simulated force and displacement curve.

The force versus displacement curves for individual SFDB model cases under the LA13 ground motion with 0.5 and 1.0 SF are presented in Figures 8 and 9, respectively. All of the SFDB models subjected to a half-scaled magnitude of the LA13 ground motion are deformed by relatively 
TABLE 2: Details of Los Angeles ground motions with a probability of exceedance of $10 \%$ in 50 years.

\begin{tabular}{|c|c|c|c|c|c|c|}
\hline Ground motion ID & EQ record & Richter scale & Distance $(\mathrm{km})$ & Duration $(\mathrm{sec})$ & Max PGA (g) & Min PGA (g) \\
\hline LA01 & 1940 El Centro (Imperial Valley) & 6.9 & 10 & 39 & 0.46 & -0.36 \\
\hline LA02 & 1940 El Centro (Imperial Valley) & 6.9 & 10 & 39 & 0.68 & -0.51 \\
\hline LA03 & 1979 El Centro (Imperial Valley) & 6.5 & 4.1 & 39 & 0.39 & -0.33 \\
\hline LA04 & 1979 El Centro (Imperial Valley) & 6.5 & 4.1 & 39 & 0.34 & -0.49 \\
\hline LA05 & 1979 El Centro (Imperial Valley) & 6.5 & 1.2 & 39 & 0.30 & -0.30 \\
\hline LA06 & 1979 El Centro (Imperial Valley) & 6.5 & 1.2 & 39 & 0.24 & -0.23 \\
\hline LA07 & 1992 Barstow (Landers) & 7.3 & 36 & 80 & 0.31 & -0.42 \\
\hline LA08 & 1992 Barstow (Landers) & 7.3 & 36 & 80 & 0.43 & -0.33 \\
\hline LA09 & 1992 Yermo (Landers) & 7.3 & 25 & 80 & 0.52 & -0.35 \\
\hline LA10 & 1992 Yermo (Landers) & 7.3 & 25 & 80 & 0.34 & -0.36 \\
\hline LA11 & 1989 Gilroy (Loma Prieta) & 7 & 12 & 40 & 0.60 & -0.67 \\
\hline LA12 & 1989 Gilroy (Loma Prieta) & 7 & 12 & 40 & 0.97 & -0.87 \\
\hline LA13 & 1994 Newhall (Northridge) & 6.7 & 6.7 & 60 & 0.63 & -0.68 \\
\hline LA14 & 1994 Newhall (Northridge) & 6.7 & 6.7 & 60 & 0.54 & -0.66 \\
\hline LA15 & 1994 Rinaldi RS (Northridge) & 6.7 & 7.5 & 15 & 0.47 & -0.53 \\
\hline LA16 & 1994 Rinaldi RS (Northridge) & 6.7 & 7.5 & 15 & 0.47 & -0.58 \\
\hline LA17 & 1994 Sylmar (Northridge) & 6.7 & 6.4 & 60 & 0.39 & -0.57 \\
\hline LA18 & 1994 Sylmar (Northridge) & 6.7 & 6.4 & 60 & 0.62 & -0.82 \\
\hline LA19 & 1986 North Palm Springs & 6 & 6.7 & 60 & 0.95 & -1.02 \\
\hline LA20 & 1986 North Palm Springs & 6 & 6.7 & 60 & 0.99 & -0.85 \\
\hline
\end{tabular}

TABLE 3: Details of Los Angeles ground motions with a probability of exceedance of $2 \%$ in 50 years.

\begin{tabular}{|c|c|c|c|c|c|c|}
\hline Ground motion ID & EQ record & Richter scale & Distance $(\mathrm{km})$ & Duration (sec) & Max PGA (g) & Min PGA (g) \\
\hline LA21 & 1995 Kobe & 6.9 & 3.4 & 60 & 1.28 & -0.75 \\
\hline LA22 & 1995 Kobe & 6.9 & 3.4 & 60 & 0.92 & -0.77 \\
\hline LA23 & 1989 Loma Prieta & 7 & 3.5 & 25 & 0.42 & -0.40 \\
\hline LA24 & 1989 Loma Prieta & 7 & 3.5 & 25 & 0.47 & -0.47 \\
\hline LA25 & 1994 Northridge & 6.7 & 7.5 & 15 & 0.76 & -0.87 \\
\hline LA26 & 1994 Northridge & 6.7 & 7.5 & 15 & 0.77 & -0.94 \\
\hline LA27 & 1994 Northridge & 6.7 & 6.4 & 60 & 0.63 & -0.93 \\
\hline LA28 & 1994 Northridge & 6.7 & 6.4 & 60 & 1.02 & -1.33 \\
\hline LA29 & 1974 Tabas & 7.4 & 1.2 & 50 & 0.74 & -0.81 \\
\hline LA30 & 1974 Tabas & 7.4 & 1.2 & 50 & 0.76 & -0.99 \\
\hline LA31 & Elysian Park (simulated) & 7.1 & 17.5 & 30 & 0.90 & -1.30 \\
\hline LA32 & Elysian Park (simulated) & 7.1 & 17.5 & 30 & 1.19 & -1.04 \\
\hline LA33 & Elysian Park (simulated) & 7.1 & 10.7 & 30 & 0.78 & -0.78 \\
\hline LA34 & Elysian Park (simulated) & 7.1 & 10.7 & 30 & 0.67 & -0.68 \\
\hline LA35 & Elysian Park (simulated) & 7.1 & 11.2 & 30 & 0.89 & -0.99 \\
\hline LA36 & Elysian Park (simulated) & 7.1 & 11.2 & 30 & 1.10 & -0.73 \\
\hline LA37 & Palos Verdes (simulated) & 7.1 & 1.5 & 60 & 0.71 & -0.51 \\
\hline LA38 & Palos Verdes (simulated) & 7.1 & 1.5 & 60 & 0.78 & -0.38 \\
\hline LA39 & Palos Verdes (simulated) & 7.1 & 1.5 & 60 & 0.34 & -0.50 \\
\hline LA40 & Palos Verdes (simulated) & 7.1 & 1.5 & 60 & 0.38 & -0.63 \\
\hline
\end{tabular}

smaller seismic forces and thus only reach into around yield displacement which immediately go over elastic range. For this seismic loading condition, all SFDB models have small recoverable displacement without clear discrepancy. As the SF is increased to 1.0, considerable recoverable displacement arising by recentering behavior is found at the curves. Moreover, it can be found at the curves that each of the
SFDB models differs as to energy dissipation capacity defined by envelop area. As shown in Figure 9, Case 1 model with excellent recentering capability takes a contrary position to Case 5 model having good energy dissipation capacity. Although Case 1 model $(\gamma=0.33)$ can almost recover original configuration upon unloading, the amount of energy dissipation caused by friction mechanism is least among five 


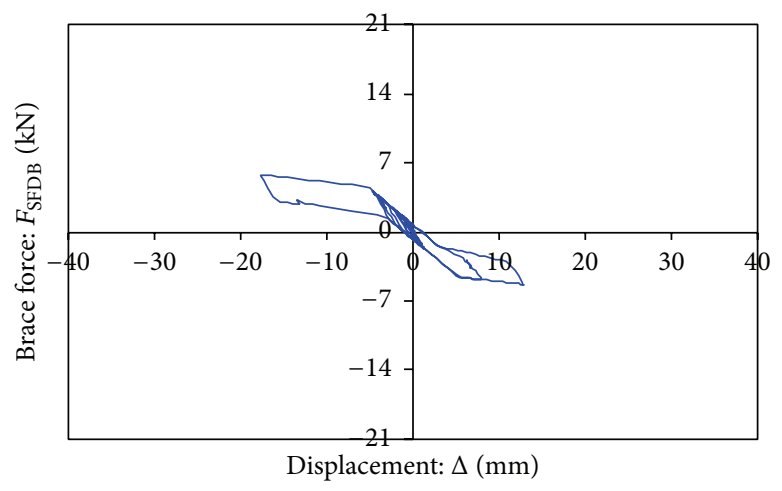

(a) Case 1 model under LA28 with $0.5 \mathrm{SF}$

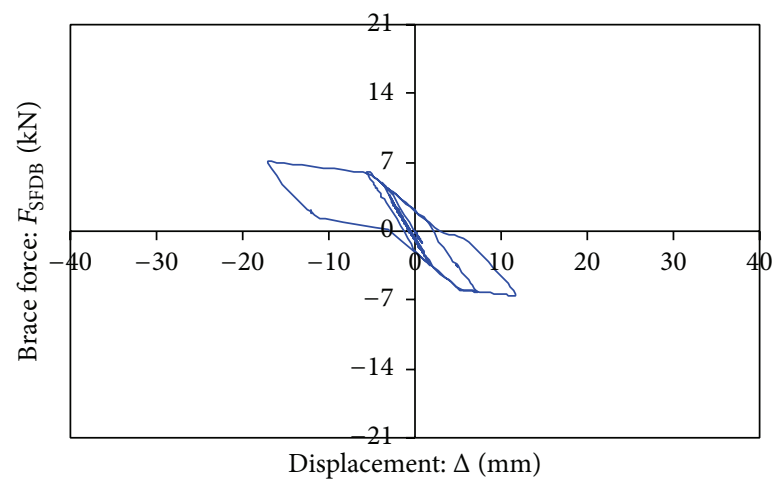

(c) Case 3 model under LA28 with $0.5 \mathrm{SF}$

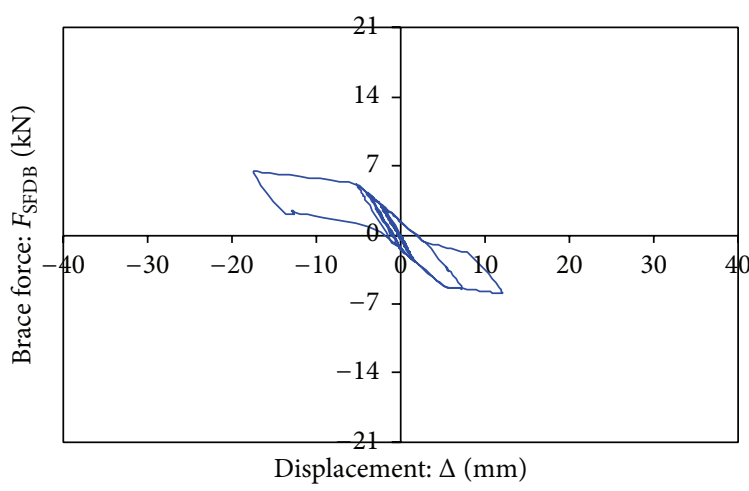

(b) Case 2 model under LA28 with $0.5 \mathrm{SF}$

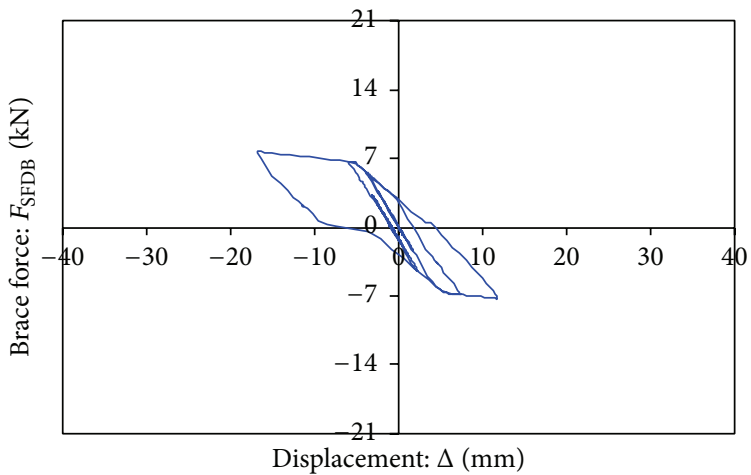

(d) Case 4 model under LA28 with $0.5 \mathrm{SF}$

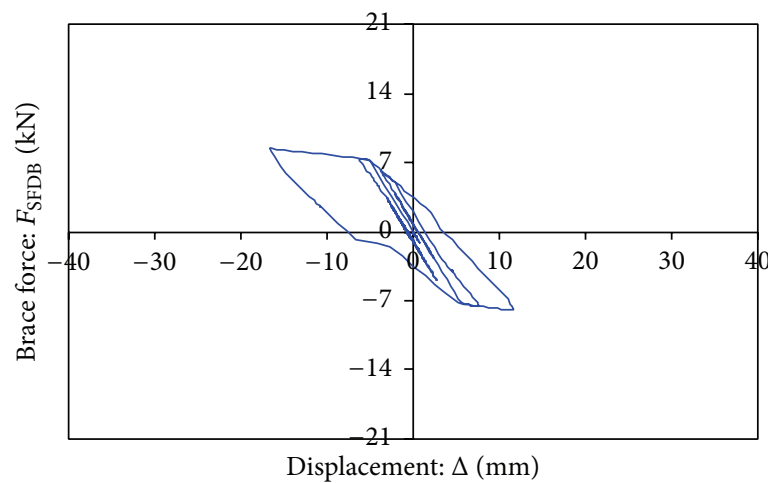

(e) Case 5 model under LA28 with $0.5 \mathrm{SF}$

FIGURE 10: Force and displacement curves for individual SFDB models under the LA28 ground motion with 0.5 SF.

model cases. Contrarily, Case 5 model $(\gamma=1.67)$ can dissipate twice as much as the energy of Case 1 model but loses all of the recentering effect. Case 3 model $(\gamma=1.00)$ shows moderate energy dissipation as well as relatively better recentering behavior.

The force versus displacement curves for individual SFDB model cases under the LA28 ground motion with 0.5 and 1.0 SF are presented in Figures 10 and 11, respectively. As we expected, all SFDB models under this ground motion generally reproduce much larger displacement than those under the LA13 ground motion. On average, maximum displacement occurring under the LA28 ground motion is twice larger compared to those under the LA13 ground motion with the same SF level. Clear recentering behavior is even found at the curve of Case 1 model subjected to the LA28 ground motion with $0.5 \mathrm{SF}$. As the SF is increased to 1.0, all SFDB models are deformed by quite large seismic forces. Therefore, ascending stiffness caused by the strength hardening of the superelastic SMA wires may occur during postyield behavior. Case 1 model possesses the largest amount of recoverable displacement among five SFDB model cases, while it dissipates the smallest amount of friction energy. Case 5 model exhibits the opposite result for recentering and energy dissipation to Case 1 model. Similar to the LA13 ground motion, Case 3 model subjected to the LA28 ground motion achieves the best efficiency with respect to the utilization of both recentering and energy dissipation to the bracing system. 


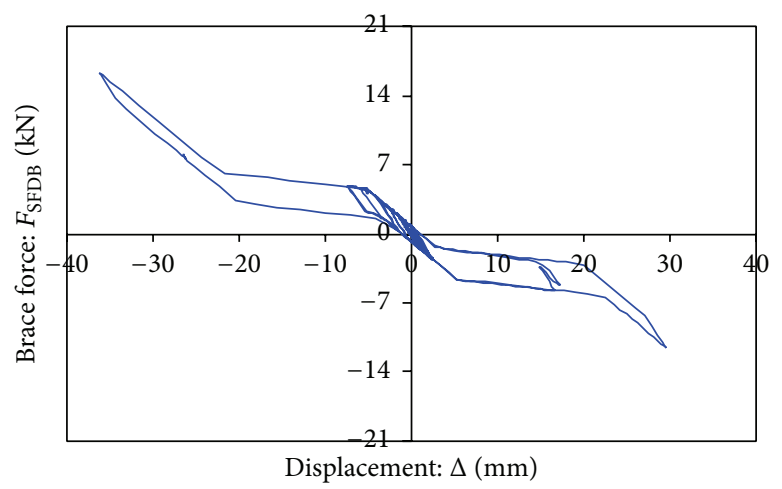

(a) Case 1 model under LA28 with $1.0 \mathrm{SF}$

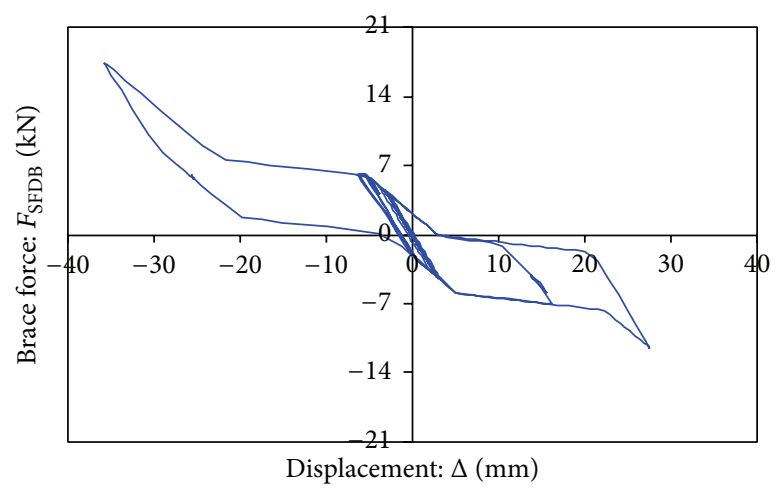

(c) Case 3 model under LA28 with $1.0 \mathrm{SF}$

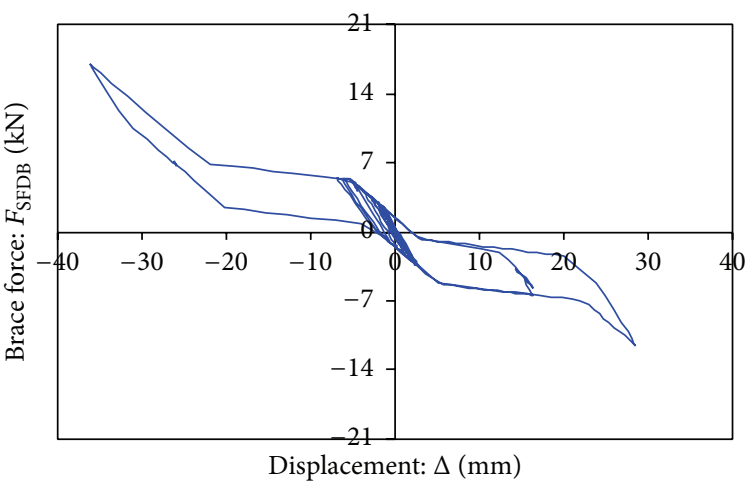

(b) Case 2 model under LA28 with $1.0 \mathrm{SF}$

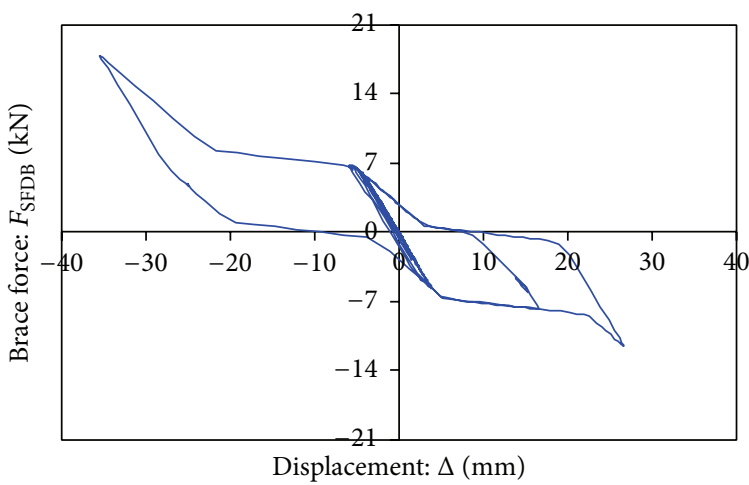

(d) Case 4 model under LA28 with $1.0 \mathrm{SF}$

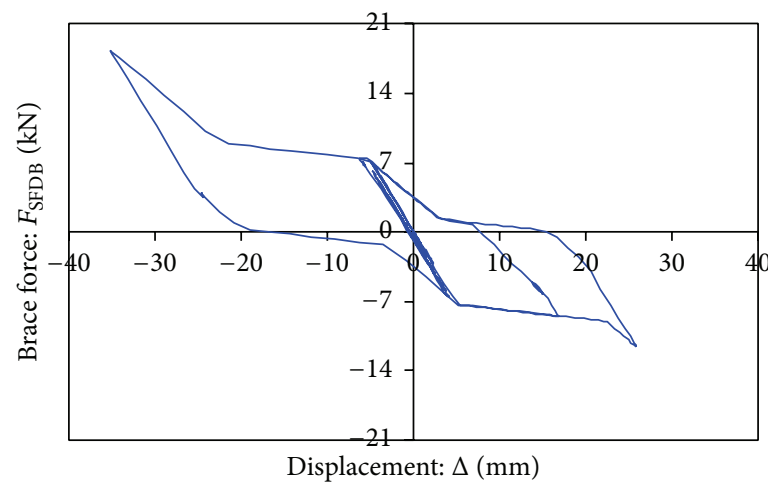

(e) Case 5 model under LA13 with $1.0 \mathrm{SF}$

FIGURE 11: Force and displacement curves for individual SFDB models under the LA28 ground motion with 1.0 SF.

\section{Performance Evaluation}

More nonlinear dynamic time-history analyses are conducted with 40 ground motion datasets in an effort to perform statistical evaluation with respect to recentering capability and energy dissipation capacity for all SFDB models presented herein. The statistical investigation of the maximum displacement for individual SFDB models subjected to 40 ground motions with two different SFs is presented in Figure 12. The solid lines indicating 15.9th, 50.0th (or median), and 84.1th percentile ranks are drawn at the graphs together with individual data points obtained from all analysis results. Other statistical values for average (AVE) and average minus-plus standard deviation
$(\mathrm{AVE} \pm \mathrm{SD})$ are expressed as the dashed lines on the graphs as well. Regardless of the SFDB model cases, statistical lines almost maintain the constant horizontal level without fluctuation at each graph. The ranges of data scatter representing the extent of uncertainty are determined by the values of standard deviation. The largest average and standard deviation values are found at the SFDB models subjected to $2 \%$ in 50-year ground motions with 1.0 SF.

The maximum brace forces $\left(F_{\mathrm{SFDB} \text {, max }}\right)$ for individual SFDB models under 40 ground motions with different SFs are given in Figure 13. As the magnitude of ground motions increases, the maximum brace forces that occur during earthquake events naturally increase as well. Case 5 model dissipating more friction energy exhibits slightly larger 


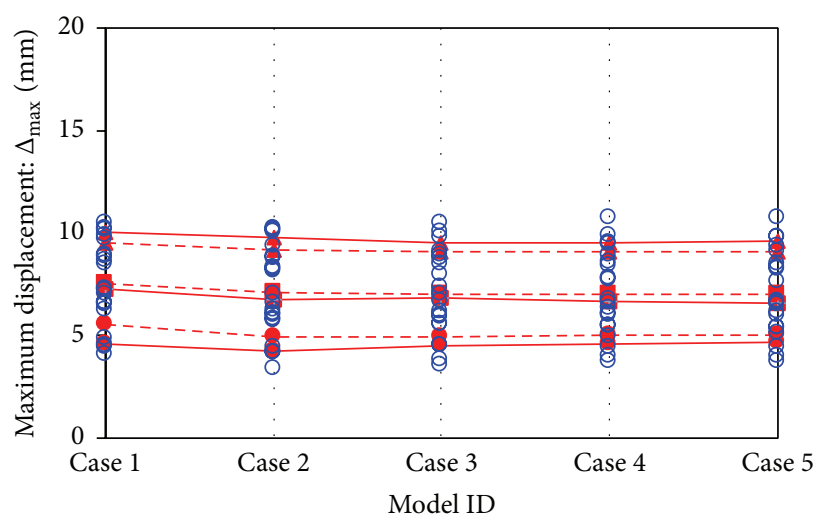

- Data point

— Percentile rank (15.9\%, 50.0\%, and 84.1\%)

- - - SD range (AVE - SD, AVE, and AVE + SD)

(a) $10 \%$ in 50 -year ground motions with 0.5 Scale Factor

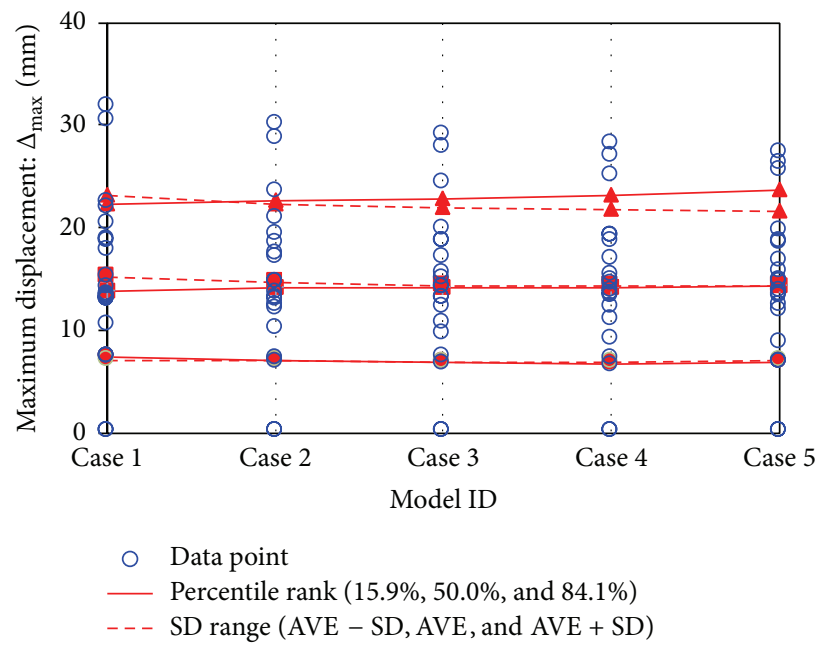

(c) $2 \%$ in 50 -year ground motions with 0.5 Scale Factor

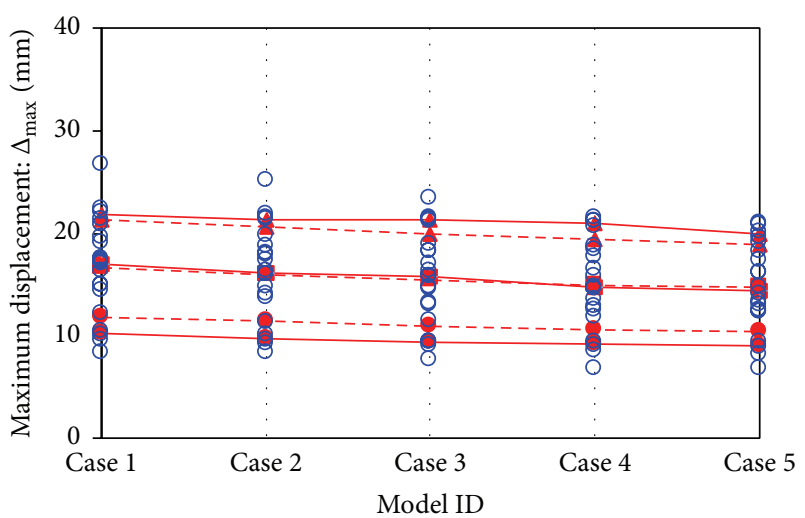

Data point

— Percentile rank (15.9\%, 50.0\%, and 84.1\%)

- - - SD range (AVE - SD, AVE, and AVE + SD)

(b) $10 \%$ in 50 -year ground motions with 1.0 Scale Factor

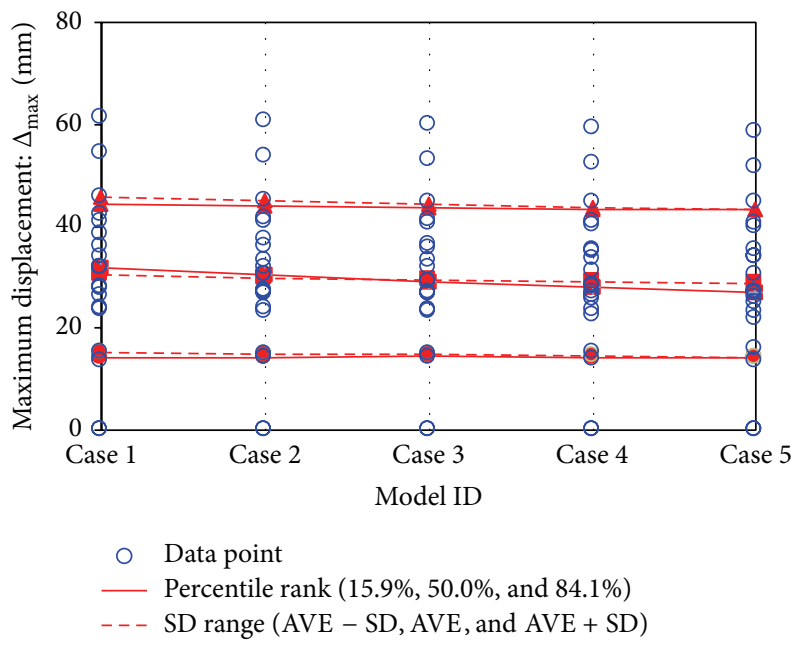

(d) $2 \%$ in 50 - year ground motions with 1.0 Scale Factor

Figure 12: Maximum displacement $\left(\Delta_{\max }\right)$ for individual SFDB models under 40 ground motions with different SFs.

statistical values for the maximum brace forces as compared to other model cases. Overall, the statistical lines steadily ascend according to the shifting from Case 1 model to Case 5 model. The largest average and standard deviation values are also found at the SFDB models subjected to $2 \%$ in 50 year ground motions with 1.0 SF. The residual displacement $\left(\Delta_{\text {res }}\right)$ for individual SFDB models under 40 ground motions with different SFs is presented in Figure 14. The distribution of obtaining residual displacement data similarly ranges from 0 to $2 \mathrm{~mm}$ at all graphs, irrespective of hazard levels and SFs. This implies that the SFDB models can generate small residual displacement even under strong seismic loading. The statistical lines rise steadily because recentering forces decrease shifting from left to right side model. Case 1 model possesses the smallest statistical values among five SFDB model cases, meaning that this model can completely recover its original configuration from strong recentering force. On the other hand, Case 5 model has the largest statistical values due to the mitigation of the recentering effect by relatively larger friction force.
The maximum recoverable displacement calculated by subtracting the permanent deformation from the maximum displacement upon unloading (e.g., $\Delta_{\max }-\Delta_{\text {rec }}$ ) is required to examine recentering capability according to system parameters (see Figure 8 for the definition of $\Delta_{\text {rec }}$ ). The recentering ratios (RRs) that can be utilized as the percentage index to estimate the self-centering capacity of individual SFDB models are converted from the maximum recoverable displacement divided by the corresponding maximum displacement as follows:

$$
\mathrm{RR}=100 \cdot \frac{\left(\Delta_{\max }-\Delta_{\mathrm{rec}}\right)}{\Delta_{\max }}
$$

The RR for individual SFDB models under 40 ground motions with different SFs are presented in Figure 15. Although Case 5 model temporarily shows good recentering performance under $10 \%$ in 50-year ground motions with $0.5 \mathrm{SF}$, which are considered to be relatively weaker magnitude, its recentering capability rapidly deteriorates under $2 \%$ 


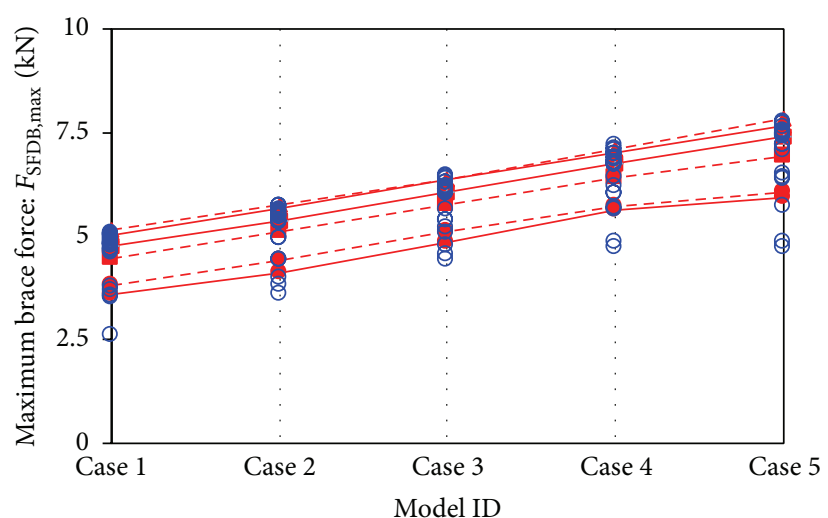

○ Data point

Percentile rank (15.9\%, 50.0\%, and 84.1\%)

- - - SD range (AVE - SD, AVE, and AVE + SD)

(a) $10 \%$ in 50 -year ground motions with 0.5 Scale Factor

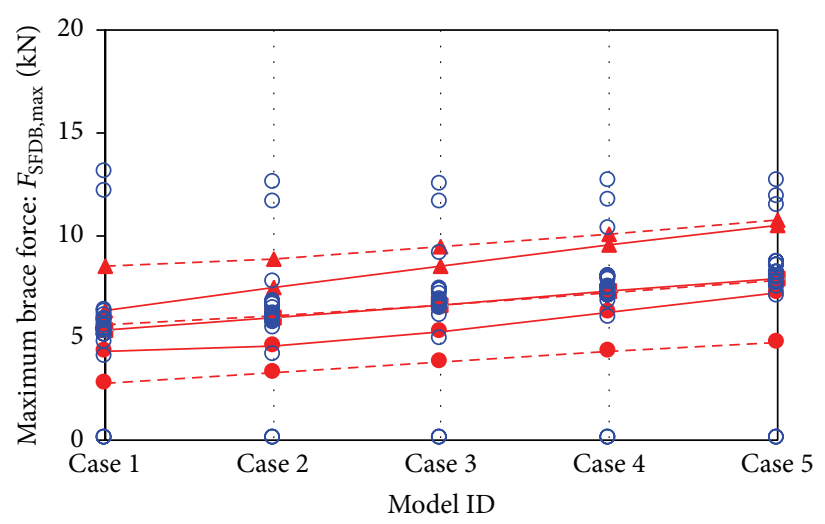

- Data point

— Percentile rank (15.9\%, 50.0\%, and 84.1\%)

- - - SD range (AVE - SD, AVE, and AVE + SD)

(c) $2 \%$ in 50 -year ground motions with 0.5 Scale Factor

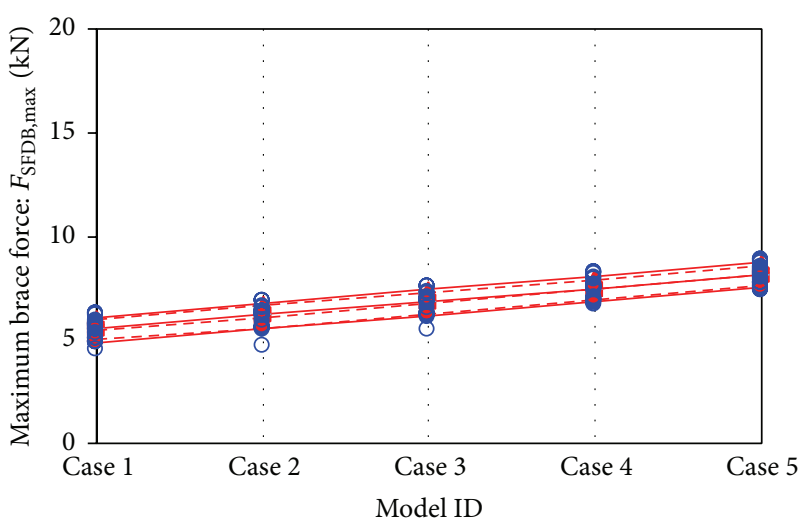

○ Data point

- Percentile rank (15.9\%, 50.0\%, and 84.1\%)

- - - SD range (AVE - SD, AVE, and AVE + SD)

(b) $10 \%$ in 50 -year ground motions with 1.0 Scale Factor

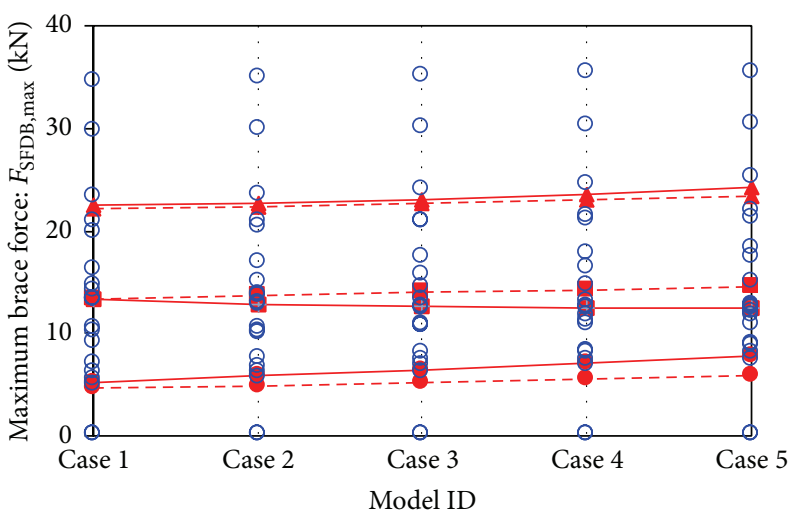

○ Data point

— Percentile rank (15.9\%, 50.0\%, and 84.1\%)

- - - SD range (AVE - SD, AVE, and AVE + SD)

(d) $2 \%$ in 50 -year ground motions with 1.0 Scale Factor

FIGURE 13: Maximum brace forces $\left(F_{\mathrm{SFDB}, \max }\right)$ for individual SFDB models under 40 ground motions with different SFs.

in 50-year ground motions. As we expected, Case 1 model possesses the best recentering performance characterized by the large value of the RRs. However, a little discrepancy between Case 1 model and Case 3 model is displayed at the RR graph under strong ground motions.

The statistical values for individual model cases under two set levels of ground motions are summarized in Tables 4 and 5. Under the same SF, the SFDB models subjected to $2 \%$ in 50 -year ground motions usually generate larger statistical values for maximum displacement and brace forces in comparison with those subjected to $10 \%$ in 50 -year ground motions. The residual displacement subjected to 1.0 -scaled ground motions is generally larger than that subjected to $0.5-$ scaled ground motions. The average (AVE) of the residual displacement results in good statistical values to support this argument. However, some exception was found for the average of residual displacement, which appears to be slightly greater for the 0.5 -scaled MCE level as compared to the 1.0-scaled MCE level (e.g., Case 4 model), because residual displacement majorly occurs at the friction dampers subjected to strong ground motions. Case 4 model which was designed with relatively weaker recentering force as compared to friction forces undergoes considerable residual displacement even under 0.5-scaled MCE ground motions. Contrary to Case 1 model, Case 5 model has statistical values taken as the largest brace forces, largest maximum or residual displacement, and smallest RRs as can be seen in the tables. Overall, Case 3 model that was designed with recentering force equal to friction force includes moderate trends for statistical distributions. It is thus concluded that friction force should be adjusted to recentering force in order to make the utmost use of self-centering effect and energy dissipation at the seismic response of the brace member.

\section{Conclusions}

In this study, seismic response and performance for selfcentering friction damping brace (SFDB) members are 
TABLE 4: Summary of statistical values for individual model cases under $10 \%$ in 50 -year ground motions.

\begin{tabular}{|c|c|c|c|c|c|c|c|c|c|c|c|c|c|}
\hline \multirow{2}{*}{$\begin{array}{l}\text { Evaluation } \\
\text { item }\end{array}$} & \multirow{2}{*}{ Model ID } & \multicolumn{6}{|c|}{$\mathrm{SF}=0.5$} & \multicolumn{6}{|c|}{$\mathrm{SF}=1.0$} \\
\hline & & $15.90 \%$ & $50.00 \%$ & $84.10 \%$ & AVE - SD & AVE & $\mathrm{AVE}+\mathrm{SD}$ & $15.90 \%$ & $50.00 \%$ & $84.10 \%$ & $\mathrm{AVE}-\mathrm{SD}$ & AVE & $\mathrm{AVE}+\mathrm{SD}$ \\
\hline \multirow{5}{*}{$\Delta_{\max }(\mathrm{mm})$} & Case 1 & 4.61 & 7.25 & 10.08 & 5.50 & 7.53 & 9.56 & 10.14 & 17.03 & 21.80 & 11.82 & 16.57 & 21.32 \\
\hline & Case 2 & 4.25 & 6.78 & 9.80 & 4.97 & 7.07 & 9.18 & 9.73 & 16.13 & 21.37 & 11.42 & 16.00 & 20.59 \\
\hline & Case 3 & 4.50 & 6.85 & 9.52 & 4.94 & 7.00 & 9.06 & 9.38 & 15.68 & 21.30 & 10.98 & 15.47 & 19.97 \\
\hline & Case 4 & 4.62 & 6.67 & 9.49 & 5.02 & 7.04 & 9.05 & 9.15 & 14.68 & 20.93 & 10.58 & 14.96 & 19.35 \\
\hline & Case 5 & 4.66 & 6.60 & 9.62 & 5.02 & 7.05 & 9.09 & 9.03 & 14.32 & 19.94 & 10.39 & 14.64 & 18.90 \\
\hline \multirow{5}{*}{$F_{\text {SFDB }}(\mathrm{kN})$} & Case 1 & 3.59 & 4.75 & 5.01 & 3.81 & 4.48 & 5.14 & 4.87 & 5.55 & 6.06 & 4.99 & 5.48 & 5.96 \\
\hline & Case 2 & 4.11 & 5.36 & 5.69 & 4.43 & 5.09 & 5.75 & 5.51 & 6.22 & 6.74 & 5.54 & 6.09 & 6.63 \\
\hline & Case 3 & 4.87 & 6.05 & 6.35 & 5.11 & 5.74 & 6.37 & 6.16 & 6.87 & 7.41 & 6.20 & 6.74 & 7.28 \\
\hline & Case 4 & 5.64 & 6.74 & 7.03 & 5.71 & 6.41 & 7.11 & 6.80 & 7.48 & 8.08 & 6.94 & 7.43 & 7.91 \\
\hline & Case 5 & 5.93 & 7.39 & 7.67 & 6.06 & 6.95 & 7.84 & 7.50 & 8.11 & 8.75 & 7.62 & 8.10 & 8.57 \\
\hline \multirow{5}{*}{$\Delta_{\text {res }}(\mathrm{mm})$} & Case 1 & 0.02 & 0.09 & 0.30 & 0.02 & 0.15 & 0.32 & 0.03 & 0.20 & 0.54 & 0.01 & 0.25 & 0.49 \\
\hline & Case 2 & 0.05 & 0.22 & 0.57 & 0.06 & 0.29 & 0.52 & 0.03 & 0.18 & 0.60 & 0.04 & 0.31 & 0.65 \\
\hline & Case 3 & 0.06 & 0.30 & 0.68 & 0.09 & 0.39 & 0.69 & 0.09 & 0.22 & 0.81 & 0.03 & 0.39 & 0.75 \\
\hline & Case 4 & 0.07 & 0.24 & 0.98 & 0.01 & 0.42 & 0.82 & 0.06 & 0.43 & 1.02 & 0.07 & 0.51 & 0.95 \\
\hline & Case 5 & 0.12 & 0.33 & 0.83 & 0.11 & 0.41 & 0.71 & 0.11 & 0.68 & 1.31 & 0.19 & 0.71 & 1.24 \\
\hline \multirow{5}{*}{ RR (\%) } & Case 1 & 79.0 & 86.3 & 90.0 & 81.3 & 85.6 & 90.0 & 89.1 & 93.5 & 95.0 & 89.6 & 92.5 & 95.4 \\
\hline & Case 2 & 68.3 & 75.6 & 80.9 & 70.2 & 74.9 & 79.7 & 80.0 & 87.8 & 90.8 & 82.2 & 86.5 & 90.9 \\
\hline & Case 3 & 68.9 & 73.5 & 86.2 & 68.8 & 75.7 & 82.6 & 69.9 & 81.8 & 85.7 & 73.4 & 80.3 & 87.2 \\
\hline & Case 4 & 71.1 & 79.4 & 92.7 & 71.3 & 80.7 & 90.1 & 55.5 & 58.6 & 71.9 & 54.2 & 61.3 & 68.3 \\
\hline & Case 5 & 75.8 & 87.9 & 99.1 & 76.8 & 86.5 & 96.1 & 46.2 & 60.6 & 77.9 & 48.3 & 60.8 & 73.3 \\
\hline
\end{tabular}

TABLE 5: Summary of statistical values for individual model cases under $2 \%$ in 50 -year ground motions.

\begin{tabular}{|c|c|c|c|c|c|c|c|c|c|c|c|c|c|}
\hline \multirow{2}{*}{$\begin{array}{l}\text { Evaluation } \\
\text { item }\end{array}$} & \multirow{2}{*}{ Model ID } & \multicolumn{6}{|c|}{$\mathrm{SF}=0.5$} & \multicolumn{6}{|c|}{$\mathrm{SF}=1.0$} \\
\hline & & $15.90 \%$ & $50.00 \%$ & $84.10 \%$ & AVE - SD & AVE & $\mathrm{AVE}+\mathrm{SD}$ & $15.90 \%$ & $50.00 \%$ & $84.10 \%$ & AVE - SD & AVE & $\mathrm{AVE}+\mathrm{SD}$ \\
\hline \multirow{5}{*}{$\Delta_{\max }(\mathrm{mm})$} & Case 1 & 7.41 & 13.84 & 22.30 & 7.14 & 15.14 & 23.15 & 14.27 & 32.01 & 44.52 & 15.28 & 30.42 & 45.56 \\
\hline & Case 2 & 7.06 & 14.20 & 22.58 & 7.02 & 14.69 & 22.36 & 14.33 & 30.46 & 43.95 & 14.99 & 29.95 & 44.90 \\
\hline & Case 3 & 6.92 & 14.19 & 22.83 & 6.88 & 14.39 & 21.90 & 14.45 & 29.17 & 43.58 & 14.80 & 29.57 & 44.34 \\
\hline & Case 4 & 6.81 & 14.16 & 23.08 & 6.87 & 14.30 & 21.73 & 14.34 & 28.10 & 43.33 & 14.56 & 29.17 & 43.78 \\
\hline & Case 5 & 6.90 & 14.28 & 23.62 & 6.98 & 14.30 & 21.62 & 14.33 & 27.18 & 43.21 & 14.34 & 28.79 & 43.24 \\
\hline \multirow{5}{*}{$F_{\mathrm{SFDB}}(\mathrm{kN})$} & Case 1 & 4.31 & 5.37 & 6.28 & 2.75 & 5.62 & 8.48 & 5.26 & 13.31 & 22.49 & 4.64 & 13.39 & 22.15 \\
\hline & Case 2 & 4.59 & 5.99 & 7.41 & 3.32 & 6.07 & 8.83 & 5.85 & 12.86 & 22.72 & 4.90 & 13.64 & 22.39 \\
\hline & Case 3 & 5.32 & 6.60 & 8.50 & 3.83 & 6.62 & 9.40 & 6.47 & 12.61 & 23.04 & 5.22 & 13.96 & 22.71 \\
\hline & Case 4 & 6.22 & 7.24 & 9.53 & 4.33 & 7.19 & 10.05 & 7.10 & 12.51 & 23.57 & 5.52 & 14.28 & 23.04 \\
\hline & Case 5 & 7.16 & 7.92 & 10.48 & 4.80 & 7.76 & 10.72 & 7.74 & 12.54 & 24.17 & 5.84 & 14.60 & 23.37 \\
\hline \multirow{5}{*}{$\Delta_{\text {res }}(\mathrm{mm})$} & Case 1 & 0.01 & 0.16 & 0.30 & -0.01 & 0.20 & 0.40 & 0.00 & 0.14 & 0.73 & 0.06 & 0.27 & 0.59 \\
\hline & Case 2 & 0.03 & 0.26 & 0.64 & 0.03 & 0.35 & 0.67 & 0.01 & 0.32 & 0.64 & 0.01 & 0.40 & 0.82 \\
\hline & Case 3 & 0.13 & 0.44 & 1.08 & 0.13 & 0.55 & 0.97 & 0.06 & 0.53 & 0.85 & 0.07 & 0.56 & 1.06 \\
\hline & Case 4 & 0.26 & 0.69 & 1.21 & 0.22 & 0.72 & 1.22 & 0.09 & 0.60 & 1.08 & 0.06 & 0.67 & 1.27 \\
\hline & Case 5 & 0.06 & 0.67 & 1.26 & 0.07 & 0.76 & 1.45 & 0.08 & 0.62 & 1.55 & 0.15 & 0.81 & 1.48 \\
\hline \multirow{5}{*}{$\mathrm{RR}(\%)$} & Case 1 & 90.9 & 93.8 & 96.6 & 90.0 & 93.5 & 97.0 & 95.3 & 96.5 & 97.3 & 94.5 & 96.3 & 98.1 \\
\hline & Case 2 & 82.2 & 88.6 & 93.8 & 81.3 & 88.1 & 94.9 & 91.5 & 94.1 & 96.4 & 90.3 & 93.8 & 97.3 \\
\hline & Case 3 & 72.3 & 82.4 & 93.5 & 74.6 & 83.4 & 92.3 & 87.1 & 90.9 & 96.4 & 86.0 & 91.2 & 96.3 \\
\hline & Case 4 & 56.4 & 60.3 & 78.7 & 53.0 & 66.1 & 79.3 & 60.3 & 70.7 & 82.9 & 60.2 & 72.0 & 83.8 \\
\hline & Case 5 & 42.7 & 60.5 & 85.7 & 45.2 & 63.3 & 81.4 & 40.2 & 54.3 & 70.3 & 39.1 & 56.6 & 74.0 \\
\hline
\end{tabular}




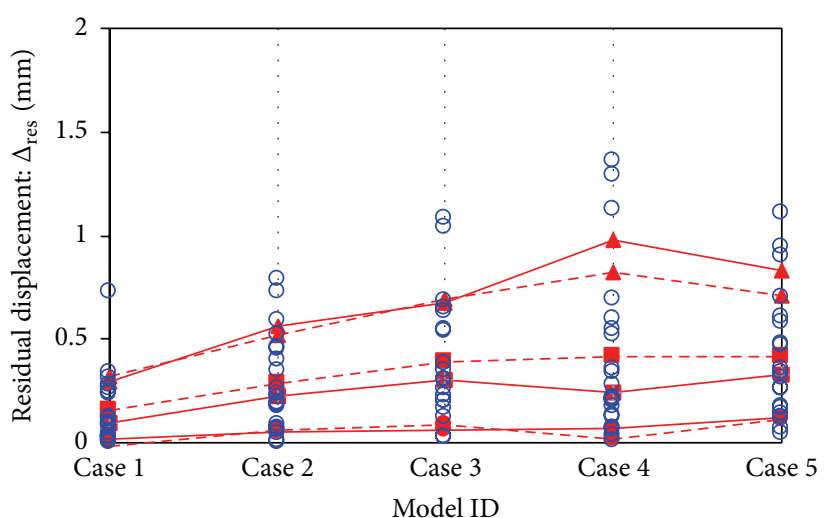

○ Data point

- Percentile rank (15.9\%, 50.0\%, and 84.1\%)

- - - SD range (AVE - SD, AVE, and AVE + SD)

(a) $10 \%$ in 50 -year ground motions with 0.5 Scale Factor

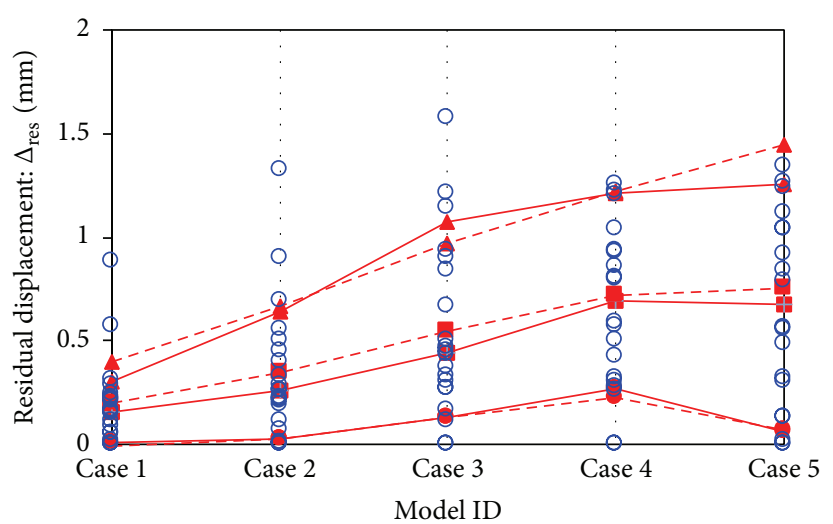

- Data point

— Percentile rank $(15.9 \%, 50.0 \%$, and $84.1 \%$ )

- - - SD range (AVE - SD, AVE, and AVE + SD)

(c) $2 \%$ in 50 -year ground motions with 0.5 Scale Factor

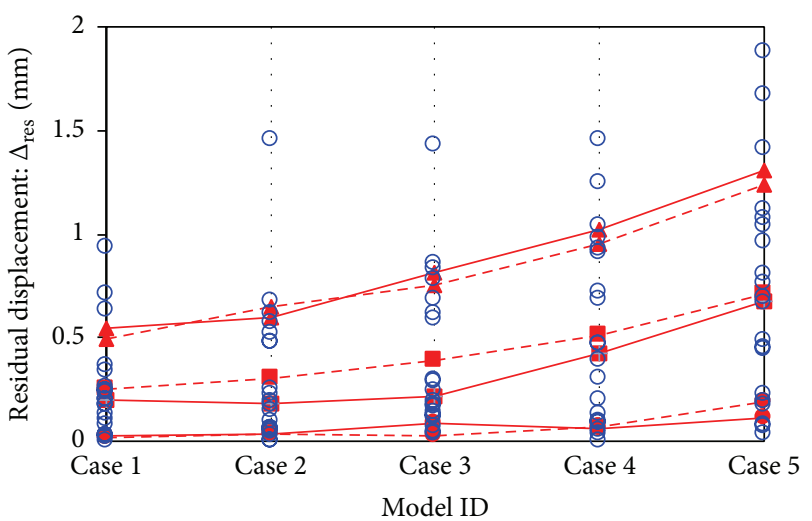

D Data point

— Percentile rank (15.9\%, 50.0\%, and 84.1\%)

- - - SD range (AVE - SD, AVE, and AVE + SD)

(b) $10 \%$ in 50 -year ground motions with 1.0 Scale Factor

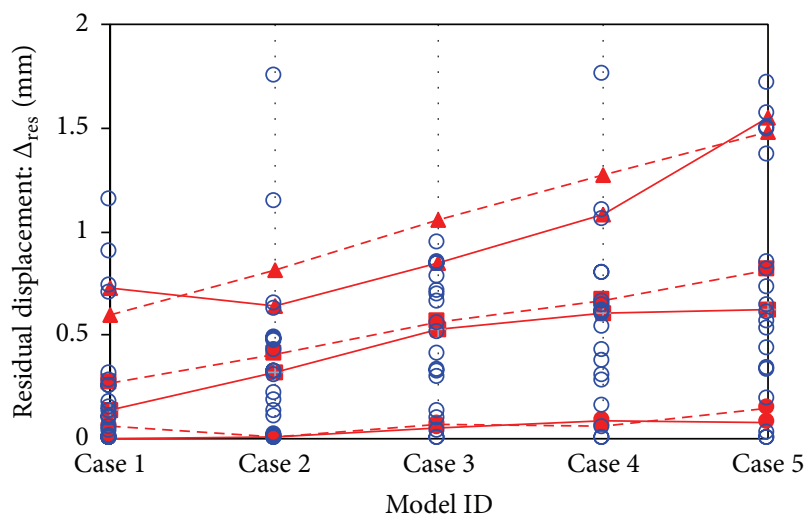

- Data point

— Percentile rank $(15.9 \%, 50.0 \%$, and $84.1 \%)$

-- - SD range (AVE - SD, AVE, and AVE + SD)

(d) $2 \%$ in 50 -year ground motions with 1.0 Scale Factor

FIGURE 14: Residual displacement $\left(\Delta_{\text {res }}\right)$ for individual SFDB models under 40 ground motions with different SFs.

mainly investigated through nonlinear dynamic time-history analyses. More conclusions are as follows.

(1) The SFDB system consists of superelastic SMA stranded wires operating as recentering devices and bolted friction dampers used for enhanced energy dissipation. The deformable contributions obtained from the inelastic behavior of SMA wires and friction dampers were separately modeled with nonlinear component springs. These nonlinear component springs were calibrated experimental data so as to verify that calibrated spring models were capable of accurately reproducing SFDB's behavior.

(2) The comparative study, which takes into account different levels of recentering capability and energy dissipation capacity, was conducted to identify optimal design parameters exerting a great influence on seismic response of the braced frame structure.
The SFDB models used for numerical analyses are classified according to the force ratio of friction force to recentering force.

(3) Case 1 model designed only with the largest recentering forces exhibits excellent recentering behavior and thus has the smallest average values of residual displacement. In addition, this model displays relatively higher statistical values for the recentering ratios (RRs) owing to larger maximum recoverable displacement. In spite of its outstanding recentering capability, the capacity of energy dissipation which absorbs impact and vibration in the SFDB system may deteriorate due to the absence of friction force.

(4) Case 5 model designed with relatively larger friction force as compared to recentering force can accommodate larger brace forces rather than other case models because of upgraded energy capacity. 

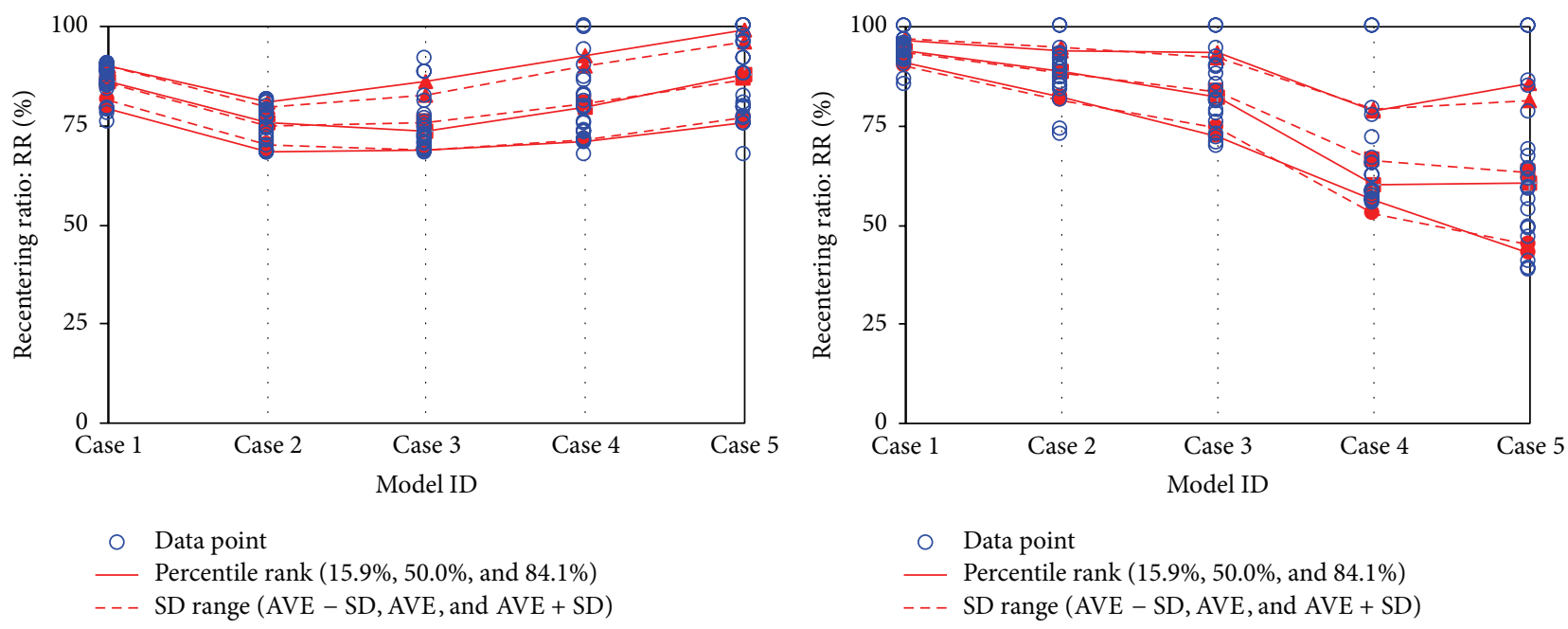

(a) $10 \%$ in 50 -year ground motions with 0.5 Scale Factor

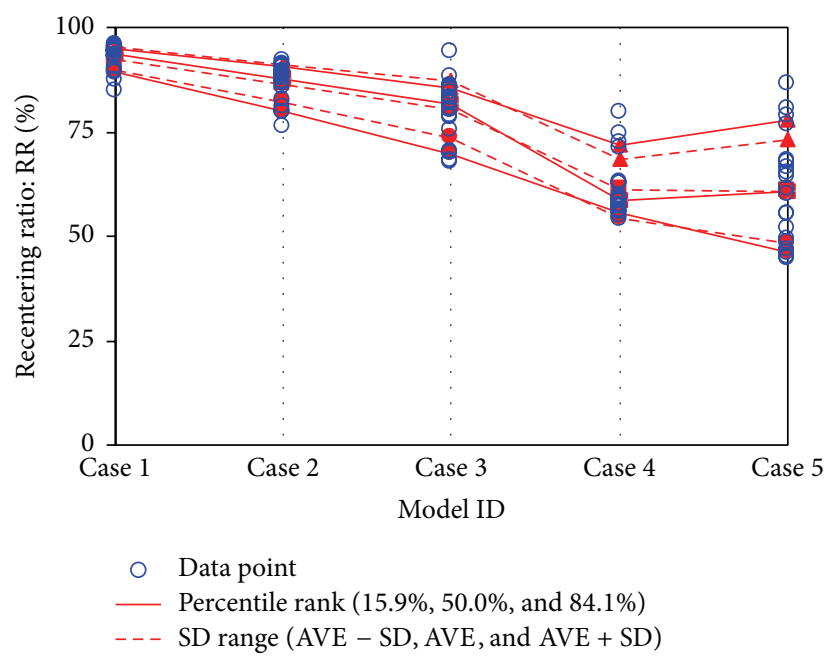

(c) $2 \%$ in 50 -year ground motions with 0.5 Scale Factor

(b) $10 \%$ in 50 -year ground motions with 1.0 Scale Factor

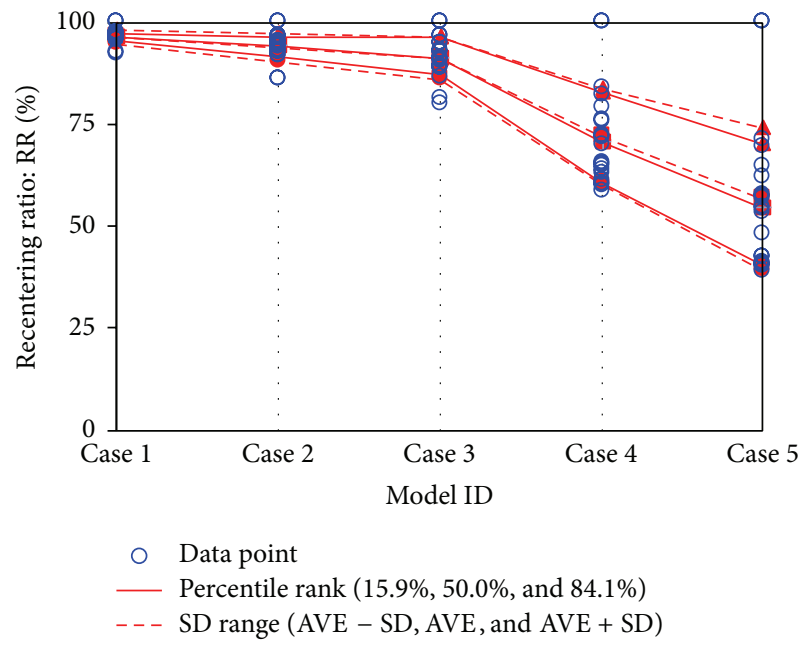

(d) $2 \%$ in 50 -year ground motions with 1.0 Scale Factor

FIGURE 15: Recentering ratios (RR) for individual SFDB models under 40 ground motions with different SFs.

On the other hand, this model confirms the fact that the increase of energy dissipation in the SFDB system has a tendency to immediately decease recoverable displacement during earthquake loading. The statistical values of relatively larger residual displacement are distributed over the model cases with larger friction force.

(5) Finally, recentering forces shall be slightly larger than or at least equal to friction forces (e.g., Case 3 model) for the purpose of achieving optimal design, which creates the decrease of permanent deformation and the increase of energy dissipation capacity. This may be established by adjusting initial bolt pretension with an aim to simply control friction forces in the SFDB system. This optimal design concept applied to smart recentering systems is verified through statistical investigation performed based on several analysis results.

\section{Conflict of Interests}

The authors declare that there is no conflict of interests regarding the publication of this paper.

\section{Acknowledgments}

This research was supported by Basic Science Research Program through the National Research Foundation of Korea (NRF) funded by the Ministry of Science, ICT, and Future Planning (Grant no. 2013R1A2A2A01068174).

\section{References}

[1] P. Uriz, F. C. Filippou, and S. A. Mahin, "Model for cyclic inelastic buckling of steel braces," Journal of Structural Engineering, vol. 134, no. 4, pp. 619-628, 2008.

[2] J. W. Hu and R. T. Leon, "Analyses and evaluations for composite-moment frames with SMA PR-CFT connections," Nonlinear Dynamics, vol. 65, no. 4, pp. 433-455, 2011. 
[3] J. W. Hu, E. Choi, and R. T. Leon, "Design, analysis and application of innovative composite PR connections between steel beams and CFT columns," Smart Materials and Structures, vol. 20, no. 2, Article ID 025019, 2011.

[4] J. W. Hu, D. K. Kim, and E. Choi, "Numerical investigation on the cyclic behavior of smart recentering clip-angle connections with superelastic shape memory alloy fasteners," Proceedings of the Institution of Mechanical Engineers Part C: Journal of Mechanical Engineering Science, vol. 227, no. 6, pp. 1315-1327, 2013.

[5] P. Uriz, Towards earthquake resistant design of concentrically braced steel buildings [Ph.D. thesis], University of California, Berkeley, Berkeley, Calif, USA, 2005.

[6] R. Sabelli, "Research on improving the design and analysis of earthquake-resistant steel-braced frames," The 2000 NEHRP Professional Fellowship Report, EERI, Oakland, Calif, USA, 2001.

[7] R. Sabelli, S. Mahin, and C. Chang, "Seismic demands on steel braced frame buildings with buckling-restrained braces," Engineering Structures, vol. 25, no. 5, pp. 655-666, 2003.

[8] R. Sabelli, "Recommended provisions for buckling-restrained braced frames," AISC Engineering Journal, vol. 41, no. 4, pp. 155$175,2004$.

[9] T. T. Soong and G. F. Dargush, Passive Energy Dissipation Systems in Structural Engineering, John Wiley \& Sons, New York, NY, USA, 1997.

[10] C. Christopoulos and A. Filiatrault, Principles of Passive Supplemental Damping and Seismic Isolation, IUSS Press, Pavia, Italy, 2006.

[11] R.-H. Zhang, T. T. Soong, and P. Mahmoodi, "Seismic response of steel frame structures with added viscoelastic dampers," Earthquake Engineering \& Structural Dynamics, vol. 18, no. 3, pp. 389-396, 1989.

[12] N. Makris, G. F. Dargush, and M. C. Constantinou, "Dynamic analysis of viscoelastic fluid dampers," Journal of Engineering Mechanics, vol. 121, no. 10, pp. 1114-1121, 1995.

[13] G. Pekcan, J. B. Mander, and S. S. Chen, "The seismic response of a 1:3 scale model R.C. Structure with elastomeric spring dampers," Earthquake Spectra, vol. 11, no. 2, pp. 249-267, 1995.

[14] S. Sorace and G. Terenzi, "Non-linear dynamic modelling and design procedure of FV spring-dampers for base isolation," Engineering Structures, vol. 23, no. 12, pp. 1556-1567, 2001.

[15] S. Sorace and G. Terenzi, "Seismic protection of frame structures by fluid viscous damped braces," Journal of Structural Engineering, vol. 134, no. 1, pp. 45-55, 2008.

[16] A. S. Whittaker, V. V. Bertero, C. L. Thompson, and L. J. Alonso, "Seismic testing of steel plate energy dissipation devices," Earthquake Spectra, vol. 7, no. 4, pp. 563-604, 1991.

[17] K.-C. Tsai, H.-W. Chen, C.-P. Hong, and Y.-F. Su, "Design of steel triangular plate energy absorbers for seismic-resistant construction," Earthquake Spectra, vol. 9, no. 3, pp. 505-528, 1993.

[18] C. E. Grigorian, T. S. Yang, and E. P. Popov, "Slotted bolted connection energy dissipators," Earthquake Spectra, vol. 9, no. 3, pp. 491-504, 1993.

[19] I. H. Mualla and B. Belev, "Performance of steel frames with a new friction damper device under earthquake excitation," Engineering Structures, vol. 24, no. 3, pp. 365-371, 2002.

[20] J. W. Hu, R. T. Leon, and T. Park, "Mechanical models for the analysis of bolted T-stub connections under cyclic loads," Journal of Constructional Steel Research, vol. 78, pp. 45-57, 2012.
[21] J. W. Hu, R. T. Leon, and T. H. Park, "Mechanical modeling of bolted T-stub connections under cyclic loads part I: stiffness modeling," Journal of Constructional Steel Research, vol. 67, no. 11, pp. 1710-1718, 2011.

[22] J.-W. Hu, Y.-S. Kang, D.-H. Choi, and T. Park, "Seismic design, performance, and behavior of composite-moment frames with steel beam-to-concrete filled tube column connections," International Journal of Steel Structures, vol. 10, no. 2, pp. 177-191, 2010.

[23] J. W. Hu, "Seismic analysis and evaluation of several recentering braced frame structures," Proceedings of the Institution of Mechanical Engineers, Part C: Journal of Mechanical Engineering Science, vol. 228, no. 5, pp. 781-798, 2014.

[24] I. D. Aiken and J. Kelly, "Earthquake simulator testing and analytical studies of two energy-absorbing systems for multistory structures," Tech. Rep. UCB/EERC-90/03, University of California, Berkeley, Calif, USA, 1990.

[25] D. K. Nims, P. J. Richter, and R. E. Bachman, "The use of the energy dissipating restraint for seismic hazard mitigation," Earthquake Spectra, vol. 9, no. 3, pp. 467-489, 1993.

[26] E. J. Graesser and F. A. Cozzarelli, "Multidimensional models of histeretic material behaviour for vibration analysis of shape memory energy absorbing devices," Tech. Rep. NCEER-890018, National Center for Earthquake Engineering, Buffalo, NY, USA, 1989.

[27] G. Song, N. Ma, and H.-N. Li, "Applications of shape memory alloys in civil structures," Engineering Structures, vol. 28, no. 9, pp. 1266-1274, 2006.

[28] P. Clark, I. Aiken, J. Kelly, M. Higashino, and R. Krumme, "Experimental and analytical studies of shape-memory alloy dampers for structural control," in Smart Structures and Materials 1995: Passive Damping, vol. 2445 of Proceedings of SPIE, $\mathrm{p}$. 241, San Diego, Calif, USA, February 1995.

[29] S. Zhu and Y. Zhang, "Seismic analysis of concentrically braced frame systems with self-centering friction damping braces," Journal of Structural Engineering, vol. 134, no. 1, pp. 121-131, 2008.

[30] R. Desroches, J. McCormick, and M. Delemont, "Cyclic properties of superelastic shape memory alloy wires and bars," Journal of Structural Engineering, vol. 130, no. 1, pp. 38-46, 2004.

[31] M. Dolce and D. Cardone, "Mechanical behaviour of shape memory alloys for seismic applications 2. Austenite NiTi wires subjected to tension," International Journal of Mechanical Sciences, vol. 43, no. 11, pp. 2657-2677, 2001.

[32] J. W. Hu, "Numerical simulation for the behavior of superelastic shape memory alloys," Journal of Mechanical Science and Technology, vol. 27, no. 2, pp. 381-386, 2013.

[33] V. A. Chernenko, V. A. L'vov, E. Cesari, A. Kosogor, and J. M. Barandiaran, "Transformation volume effects on shape memory alloys," Metals, vol. 3, no. 3, pp. 237-282, 2013.

[34] S. Mazzoni, F. Mckenna, and G. L. Fenves, OpenSEES Command Language Manual v. 1.7.3, Department of Civil Environmental Engineering, University of California, Berkeley, Calif, USA, 2006.

[35] F. Auricchio and E. Sacco, "A one-dimensional model for superelastic shape-memory alloys with different elastic properties between austenite and martensite," International Journal of Non-Linear Mechanics, vol. 32, no. 6, pp. 1101-1114, 1997.

[36] P. G. Somerville, N. Smith, S. Punyamurthula, and J. Sun, "Development of ground motion time histories for phase 2 of the FEMA/SAC steel project," SAC Background Document SAC/BD97/04, 1997. 

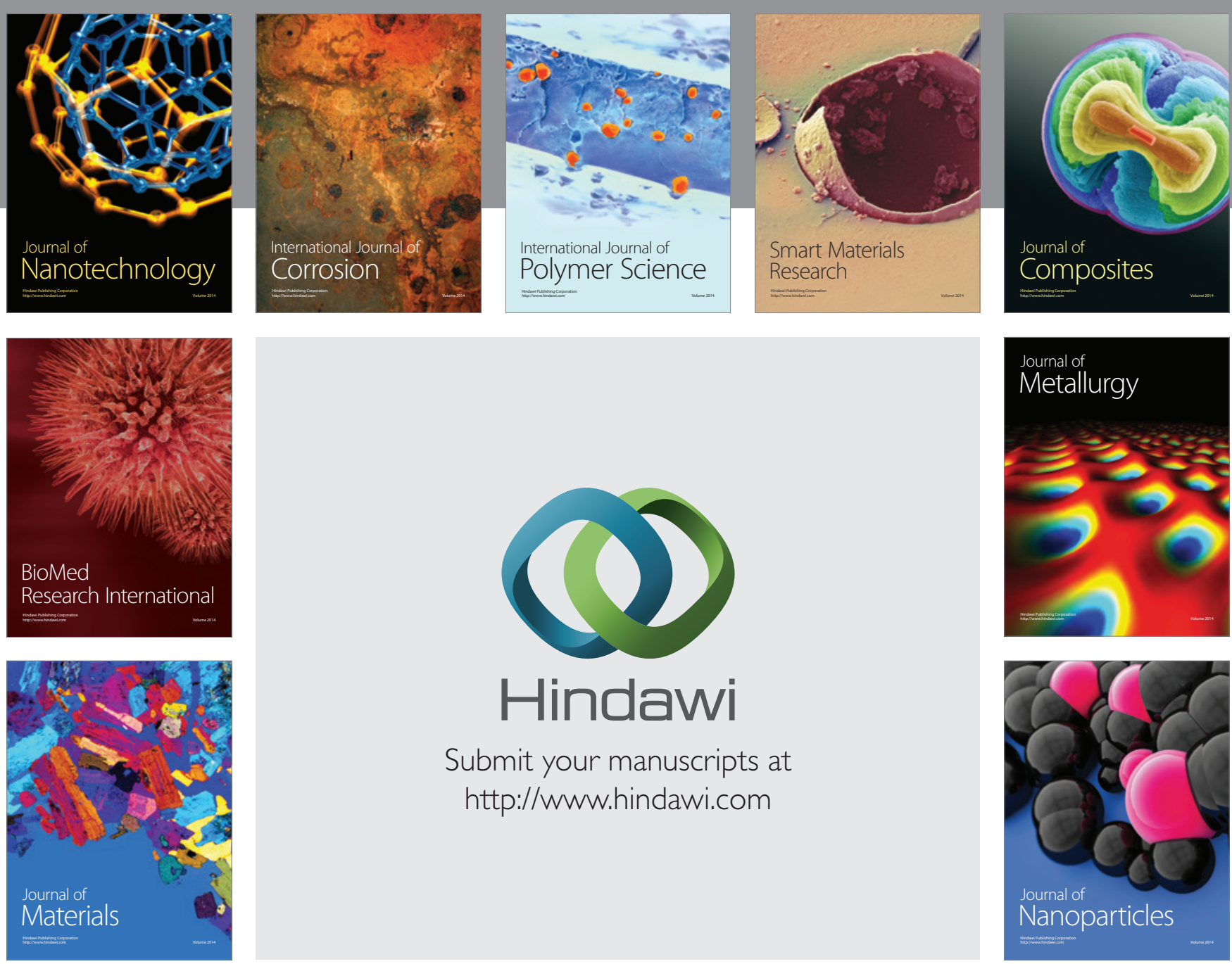

Submit your manuscripts at http://www.hindawi.com
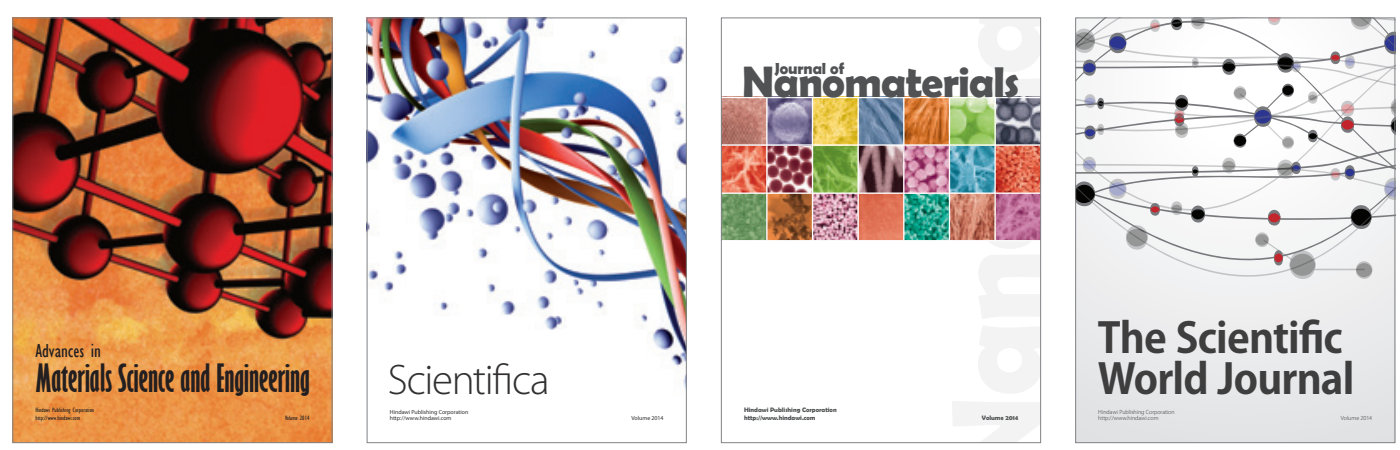

\section{The Scientific World Journal}
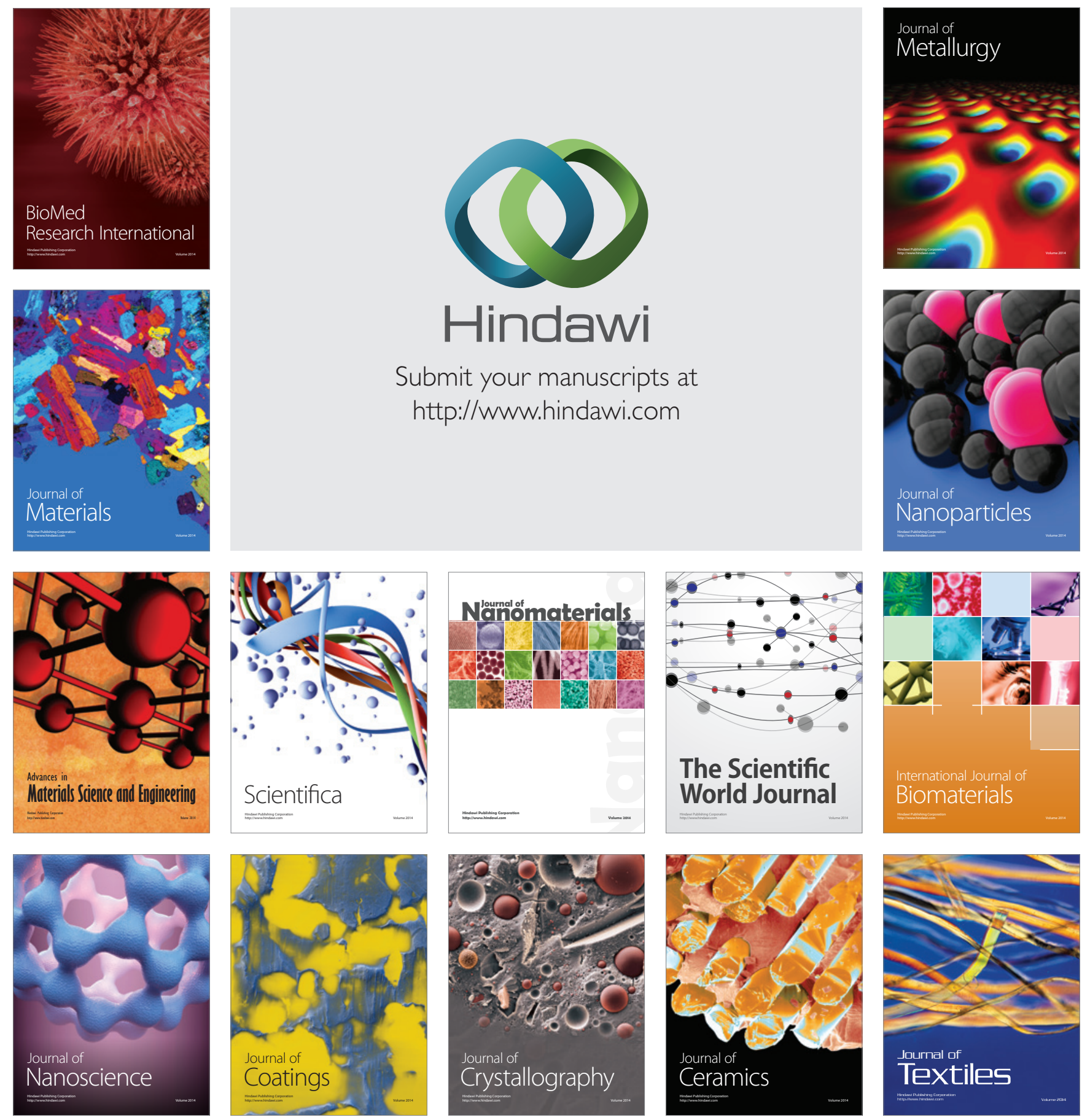